\title{
An assessment of the performance of scenarios against historical global emissions for IPCC reports
}

\author{
Jiesper Strandsbjerg Tristan Pedersen ${ }^{\mathrm{a}, \mathrm{b}, *}$, Filipe Duarte Santos ${ }^{\mathrm{a}}$, Detlef van Vuuren ${ }^{\mathrm{c}}$, \\ Joyeeta Gupta ${ }^{\mathrm{d}}$, Ricardo Encarnação Coelho ${ }^{\mathrm{e}}$, Bruno A. Aparício ${ }^{\mathrm{a}}$, Rob Swart ${ }^{\mathrm{f}}$ \\ ${ }^{a}$ Climate Change Impacts, Adaptation and Modelling (CCIAM), Centre for Ecology, Evolution and Environmental Changes (cE3c), Faculdade de Ciências da \\ Universidade de Lisboa (Faculty of Science, University of Lisbon), Campo Grande 016, C1, 2.22, 1749-016 Lisbon, Portugal \\ ${ }^{\mathrm{b}}$ Instituto de Ciências Sociais da Universidade de Lisboa (ICS-UL) (Social Science Institute of the University of Lisbon), Av. Professor Aníbal de Bettencourt 9, $1600-189$ \\ Lisbon, Portugal \\ ${ }^{\mathrm{c}}$ PBL Netherlands Environmental Assessment Agency, Den Hague, the Netherlands \\ ${ }^{\mathrm{d}}$ Governance and Inclusive Development, Geography, Planning and International Development Studies, AISSR, University of Amsterdam, the Netherlands \\ e Changes, Centre for Ecology, Evolution and Environmental Changes (cE3c), Faculty of Sciences of the University of Lisbon, Portugal \\ ${ }^{\mathrm{f}}$ Wageningen Environmental Research, Wageningen, the Netherlands
}

\section{A R T I C L E I N F O}

\section{Keywords:}

Emissions scenarios

Intergovernmental Panel on Climate Change Emission scenarios against historical trends Socioeconomic trends

Global

Non-OECD/OECD

\begin{abstract}
A B S T R A C T
Long-term emissions scenarios have served as the primary basis for assessing future climate change and response strategies. Therefore, it is important to regularly reassess the relevance of emissions scenarios in light of changing global circumstances and compare them with long-term developments to determine if they are still plausible, considering the newest insights. Four scenario series, SA90, IS92, SRES, and RCP/SSP, were central in the scenario-based literature informing the five Assessment Reports of the Intergovernmental Panel on Climate Change (IPCC) and the sixth assessment cycle. Here we analyze the historical trends of carbon dioxide (CO2) emissions from fossil fuel combustion and industry and emissions drivers between 1960 and 2017 . We then compare the emission scenario series with historical trends for the period 1990-2017/2018. The results show that historical trends are quite consistent with medium scenarios in each series. As a result, they can be regarded as valid inputs for past and future analyses of climate change and impacts. Global CO2 emissions 1960-2018 (and 1990-2018) comprised six (and three) overall subperiods of emissions growth significantly higher and lower than average. Historically, $\mathrm{CO} 2$ emissions (in absolute numbers and growth rate) are tightly coupled with primary energy and indirectly with GDP. Global emissions generally followed a medium-high pathway, captured by "middle-of-the-road" scenario narratives in the earlier series, and by combinations of "global-sustainability" and "middle-of-the-road" narratives in the most recent series (SRES and SSP-baselines). Historical non-OECD trends were best captured by "rapid-growth" and "regional-competition" scenarios, while OECD trends were close to regional-sustainability and global-sustainability scenarios. Areas where the emissions scenarios captured the historical trends less well, are renewable and nuclear primary energy supply. The fact that the actual historical development is consistent with rapid-growth narratives in the non-OECD regions might have important implications for future greenhouse gas emissions and associated climatic change.
\end{abstract}

\section{Introduction and background}

Emissions scenarios form a key tool in the scenario-based literature, informing the Intergovernmental Panel on Climate Change's (IPCC) assessments (IPCC, 1990; Moss et al., 2010). The history of IPCC assessment reports now covers several generations of emissions scenarios. These include the "1990 IPCC First Scientific Assessment"
(SA90), (IPCC, 1990), the "1992 IPCC Scenarios" (IS92) (Leggett et al., 1992), and the 2000 "Special Report on Emissions Scenarios" (SRES) (Nakicenovic and Swart, 2000). They also include more recent emissions scenarios developed outside the IPCC (Moss et al., 2010), i.e., the "Representative Concentration Pathways" (RCPs) (van Vuuren et al., 2011) and the "Shared Socioeconomic Pathways" (SSPs) (O'Neill et al., 2014; Riahi et al., 2017).

\footnotetext{
* Corresponding author at: CCIAM, Faculdade de Ciências da Universidade de Lisboa (FCUL) Campo Grande, Edifício C1, 1749-016 Lisboa, Portugal.

E-mail address: jiespertristan@gmail.com (J. Strandsbjerg Tristan Pedersen).
} 
These emission scenarios aim to explore possible trajectories. They include those trajectories that are consistent with current expectations, as well as more uncertain developments that show trajectories that would meet specific goals (IPCC, 2014b) or explore possible high impact futures (Moss et al., 2010; Riahi et al., 2017; van Vuuren et al., 2011). They are not predictions - as the future is fundamentally uncertain. This uncertainty is a key reason to explore multiple scenarios. Simultaneously, emissions scenarios should be plausible in economic structures, demographics (O'Neill et al., 2017), and energy systems (Bauer et al., 2017).

Therefore, it is important to regularly reassess the relevance of emissions scenarios in light of changing global circumstances (Peters et al., 2013; Richels et al., 2008; van Vuuren et al., 2010); to compare them with long-term developments; determine if they are still plausible; considering the newest insights. One way to do so is to compare observed emission trends with emission scenarios to inform and update the outlook of various futures being realized. These comparisons can provide information on whether scenario updates are needed and compare emission trajectories against goals, such as the 2015 Paris Agreement on Climate Change.

More than ten years ago, Van Vuuren and O'Neill (2006) conducted the first quantitative evaluation of the emissions scenarios by comparing the socioeconomic drivers and greenhouse gas (GHG) emissions projected in the SRES set with historical data for the 1990-2000 period. Later, researchers argued that the observed growth in fossil-fuel and industry $\mathrm{CO}_{2}$ emissions was higher than in most fossil-fuel intensive SRES scenarios. The researchers argued that this high-growth was caused by a turnaround of earlier declining trends in the energy intensity (Raupach et al., 2007) and unforeseen local shifts in emissions caused by unanticipated GDP growth in Asia and Eastern Europe (Pretis and Roser, 2017). Additionally, some questioned if the RCPs' high end of emissions ranges were too low (Peters et al., 2013).

From a policy perspective, these arguments are critical because the scenario ranges are often used in the context of the United Nations Framework Convention on Climate Change (UNFCCC) negotiations and associated national and international climate policies. However, shortterm observations are not necessarily good indicators of long-term future emission trajectories. Evaluating the reasons for the differences requires distinguishing between short-term developments and the longterm trends on which the emissions scenarios are based (Manning et al., 2010; van Vuuren et al., 2010). In 2020, we have almost thirty years of historical data available for a longer-term assessment of the scenario sets.

This paper evaluates the four generations of emission scenario sets against historical trends in $\mathrm{CO}_{2}$ emissions and socioeconomic developments. We assess whether projections are within the emission scenario ranges during the examined period and analyze the historical relationship between emission development and socioeconomic drivers. More specifically, we address the following research questions: (1) How do actual fossil fuel and industry $\mathrm{CO}_{2}$ emissions relate to emissions drivers over a long-term period (1960-2017)? (2) How do emissions scenarios, used by IPCC in successive assessments, compare to actual emissions and drivers from 1990 to the present?

Addressing these questions contributes to a better understanding of the emissions scenarios' abilities to capture historical developments and informs the ongoing debate on the role and usefulness of emissions scenarios as a central part of the knowledge basis for assessing future climate change. The key added value over previous studies is the coverage of all four emission scenario sets and historical development analysis over a more extended period.

The paper is organized as follows: Section 2 presents the methodology and data sets used for our analysis. Section 3 compares and categorizes emissions scenarios across sets in narrative families (3.1), analyzes the historical relationship between emissions and emissions drivers 1960-2017 (3.2), and compares historical trends against scenarios (3.3). Section 4 discusses how the results relate to earlier scenario debates and the potential implications for future emissions scenario developments.

\section{Material and methods}

We performed a detailed comparison of $\mathrm{CO}_{2}$ emissions and socioeconomic variables for all emission scenario sets used for assessments for IPCC Assessment Reports (from now on, emission scenarios will be mainly referred to as scenarios). We selected five key variables, i.e., $\mathrm{CO}_{2}$ from fossil fuel and industry, population, GDP, total, and fossil primary energy. The variables were chosen because they are key scenario results in all four sets. Developments in population, economic growth, and technology (e.g., fossil/non-fossil) are used as input for determining energy use and emissions (O'Neill et al., 2017; Riahi et al., 2017) and are central in the Kaya identity for the total $\mathrm{CO}_{2}$ emissions level (Kaya and Yokobori, 1997; Nakicenovic and Swart, 2000). Moreover, $\mathrm{CO}_{2}$ from fossil fuels and industry account for $\sim 65 \%$ of global greenhouse gas emissions (IPCC, 2014a). ${ }^{1}$

First, we compare and categorize the assumptions underlying the scenario sets (SA90, IS92, SRES, and SSPs) in scenario families (based on van Vuuren et al., 2012) to group scenarios and facilitate comparison of individual scenarios across the sets. Additionally, we group scenarios by "low" (<1099 GtC), "medium-low"(1100-1429 GtC), "medium-high" (1430-1799 GtC), and "high" ( $>1800 \mathrm{GtC})$ emissions pathways based on total cumulative total $\mathrm{CO}_{2}$ emissions between 1990 and 2100 (IPCC, 2000) - to facilitate comparison of long-term developments across sets.

We calculated weighted moving averages based on eight-year estimates using equal weight filtering to compare and analyze long-term emissions trends with emission drivers. This method reduces the noise from inter-annual growth rates by "smoothing" the time sets to highlight the underlying trend (Hyndman, 2009). Additionally, we identified twelve sub-periods of low/high $\mathrm{CO}_{2}$ emission growth rates as subperiods of high growth rates $(>1 \%)$ and sub-periods of medium-low growth ( $1 \%$ or lower). Finally, we analyzed linear correlations between emissions and drivers for absolute numbers and growth rates. We used the compound annual growth rate for calculating average yearly growth rates.

We focus on "marker scenarios" (e.g., SSP baseline (SSP-BL) and SRES marker/illustrative scenarios) when we compare scenarios with historical trends. The RCPs are included in the emissions comparison, only, since they are not connected directly to specific socioeconomic drivers (van Vuuren et al., 2011). But they are essential for emissions evaluations since there is no one-to-one match between the SSPs and RCPs in the SSP-RCP structure (O'Neill et al., 2016; Riahi et al., 2017;

\footnotetext{
${ }^{1}$ Educational attainment and urbanization comprise essential elements of the SSPs (Riahi et al., 2017). However, they are not represented quantitatively in the previous sets.
} 
van Vuuren et al., 2011). ${ }^{2}$

First, we compare observed emissions with scenarios to inform and update the outlook of various futures being realized. Second, we compare the quantifications underlying the assumptions of the IS92, SRES, and SSP-BLs with the historical development of selected emission drivers and $\mathrm{CO}_{2}$ emissions (sufficient data for all key variables were not accessible for the oldest, SA90 set).

We base the socioeconomic comparisons on growth rates rather than absolute numbers because absolute start-year values differ within and across scenario databases. The scenarios generally report emissions at intervals of 5,10 , or 25 years. Thus, the method of "compound annual growth rates" (CAGR) was used since it calculates the beginning and end value, providing a consistent growth rate comparison between projections and historical developments. A sensitivity analysis suggests that CAGR is robust, compared to "average annual growth rates" (AAGR) - an often-used method (Peters et al., 2013) calculating the mean of a series of growth rates.

The databases used for analyses are presented in Table 1.

Historical estimates between 1990 and 2017 were used for all variables to compare growth rates with scenarios since this was the IEA's latest recorded year. Historical primary energy estimates differ over time because the IEA statistical methods changed in 2005 (OECD/IEA, 2005). Therefore, primary energy values also differ between scenario databases and between models. From the SSP database, we converted SSP nuclear primary energy (via the "partial substitution" method, multiplied by $1 / 0.33$ ), which is according to present IEA methodology (OECD/IEA, 2005) to provide fair comparisons between historical and

Table 1

Databases for emissions, emissions drivers, and scenarios.

\begin{tabular}{|c|c|c|}
\hline Period & Variable & Data source \\
\hline 1751-2018 & $\mathrm{CO} 2_{2}$ fossil \& Industry (global budget) & $\begin{array}{l}\text { Global Carbon Budget } \\
\text { (GCP, 2019) }\end{array}$ \\
\hline 1959-2018 & $\begin{array}{l}\text { CO2 fossil \& Industry (national } \\
\text { budgets) }\end{array}$ & $\begin{array}{l}\text { Global Carbon Project } \\
\text { (GCP (2019) }\end{array}$ \\
\hline 1960-2018 & Global population & World Bank (WB, 2019a) \\
\hline 1960-2018 & $\begin{array}{l}\text { GDP MER (Market Exchange Rates; } \\
\text { constant US\$2010) }\end{array}$ & World Bank (WB, 2019c) \\
\hline 1990-2018 & $\begin{array}{l}\text { GDP PPP (purchasing power parity; } \\
\text { constant international\$2011) }\end{array}$ & World Bank (WB, 2019c) \\
\hline 1965-2018 & Primary Energy Consumption (PEC) & BP (2018) \\
\hline 1971-2017 & Primary Energy Supply (PES) & $\begin{array}{l}\text { International Energy } \\
\text { Agency } \\
\text { (IEA, 2018; IEA, 2019a) }\end{array}$ \\
\hline 1985-2100 & SA90 & IPCC (1990) \\
\hline $1985-2100$ & IS92 & Pepper et al. (1992) \\
\hline 1990-2100 & SRES & $\begin{array}{l}\text { Nakicenovic and Swart } \\
(2000)\end{array}$ \\
\hline 2005-2100 & SSP/RCP & $\begin{array}{l}\text { Riahi et al. (2017)/van } \\
\text { Vuuren et al. (2011) }\end{array}$ \\
\hline
\end{tabular}

\footnotetext{
2 The scenario developers, authors, and modelers of the scenario sets have analyzed a broad spectrum of scenarios. A limited, representative number was eventually selected and published as so-called "marker scenarios" from these. Our analyses did not include the SSP mitigation scenarios - which were developed focusing on the forcing levels covered by the RCPs (O'Neill et al., 2016; Riahi et al., 2017). The reasons for this are that scenarios with new climate policies are still being developed (e.g., Fujimori et al., 2017; Kriegler et al., 2014) and since the IS92 and SRES do not include assumptions about climate policies beyond those already adopted at the time of scenario development (Leggett et al., 1992; Nakicenovic and Swart, 2000). The RCPs are included in the emissions comparisons only for informative reasons. A complete assessment of the RCPs is less relevant in this paper's context, as they are not directly connected to particular sets of emissions drivers. However, it is pertinent to include the RCPs in the emissions comparison since there is no one-toone match between the SSPs and RCPs in the SSP-RCP structure (O'Neill et al., 2016; Riahi et al., 2017; van Vuuren et al., 2011).
}

scenario databases. We then recalculated total and non-fossil estimates to allow for meaningful comparisons between energy projections and historical estimates. Dispite detailed data analyzes of scenario quantifications, but because of the uncertainty of the actual assumptions used by the developers of IS92 and SRES - 20 to 30 years ago - we use the original scenario primary energy data. ${ }^{3}$ We perform regional crossscenario comparisons for the non-OECD and OECD categories, as reported in the IS92, SRES (OECD90), and SSP databases (OECD90 + EU member states and candidates). ${ }^{4}$ The definitions OECD/non-OECD categories differs between sets. As such, we recalculate estimates of historical emissions and drivers according to the scenario database nonOECD and OECD categories to perform valid comparisons of regional scenarios (see Supplementary material).

\section{Results}

\subsection{Categorizing emissions scenarios: Assumptions underlying the sets}

Storylines were developed for the SRES and additionally for the SSPs. The SA90 and IS92 assumptions and quantifications can effectively be related to specific, more extensive narrative descriptions of the later sets. Despite the two earliest sets having more simplified assumptions, we categorize all emission scenarios in five scenario-families based on storylines to compare scenarios across all four sets (Table 2).

The general storylines of the scenario-families do not necessarily reflect the long-term emission trajectory. The five global sustainability scenarios have a peak-and-decline shaped trajectory, where emissions peak during the century and decline towards 2100 . Four other scenarios have a peak-and-decline pathway (two SRES rapid-growth (A1B, A1T) and one SSP regional-competition (SSP4)). The remaining scenarios keep increasing slowly (regional sustianability), moderately (middle-ofthe-road), or rapidly (rapid-growth) throughout the century. To make the differences between individual scenario quantifications transparent, we added the cumulative emissions category in parenteses for each scenerio (Table 2).

The storyline focus of the scenario sets has changed over time: from energy mix and efficiency (SA90) to population, income, and fossil fuel resources (IS92), to "regional vs. global" and "economic vs. environmental"' (SRES) (Girod et al., 2009). Most recently, there has been a shift to energy system demand and supply characteristics as a function of a set of demographic and economic drivers broader than previous scenarios,

\footnotetext{
${ }^{3}$ Comparing contemporary historical IEA records with the emission scenario sets gives reason to believe that several IS92 and SRES energy estimates could be converted to match better current IEA energy estimates (and statistical methods). The IS92 hydro estimates in 1990 are three times higher than IEA and, therefore, likely to be based on the partial substitution method. Consequently, it could be converted to physical content (multiplied by 0.36 ) to be comparable to current historical records. However, solar is almost half and nuclear is also lower compared to historical records. Renewable energy in some SRES scenarios (A1FI and B1) seems to have been using input data based on partial substitution.Additionally, A1FI was the only SRES nuclear scenario with 1990-estimates comparable with historical estimates, while the remaining five marker/illustrative scenarios have nuclear estimates about three times lower compared to historical records. For comparative reasons only, we made conversions for the scenarios mentioned here. It changed the century-long quantifications for the fossil fuel-intensive A1FI, which became lower than the balanced A1B. It is also a reason for not conversing for the earlier scenarios (See supplementary material).

4 The levels of regional aggregation differ between the sets; thus, the distinction between OECD/Non-OECD was chosen. The OECD definition differs between historical databases (OECD 2012: 36 countries), IS92 (OECD90: 24 countries \& 32 units), SSP (OECD 1990 and EU member states and candidates: 44 countries/units). Thus, for our analysis, we made the necessary adjustments - recalculating historical estimates for both the SSP OECD/non-OECD (OECD90+EU) and IS92 OECD/non-OECD (OECD90) - to compare the trends significantly (see Supplementary material).
} 
Table 2

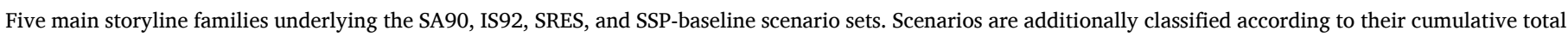

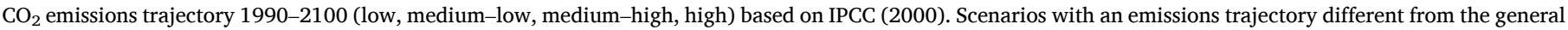

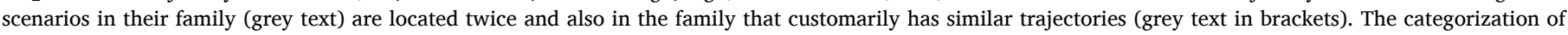

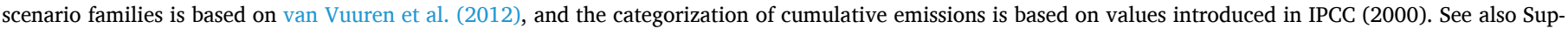
plementary Information.

Scenario narrative Families
"Global sustainability"(Low to
medium-low cumulative emissions) *
"Regional sustainability"(low to
medium-low)
"Middle of the road"(medium-high)

"Regional competition"(medium-high to high)

"Rapid growth"(high to low)
Scenario sets SA90 IS92 SRES SSP

SA90-C: Control policies

(low); SA90-D: Accelerated policies (low) SA90-B: Low emissions (low) SA90-A: High emissions (medium-high) IS92c (low) B1: global solutions (low) SSP1Global Sustainability (medium-low)

\section{IS92d (low)}

IS92a; IS92b: OECD

efficiency

(medium-high) IS92f (high)

IS92e (high)
A2: Self-reliance (high)

B2: local solutions (medium-low)

SSP2: Middle of the road (medium-high)

SSP3: Regional rivalry (medium-high); SSP4: A divided road (medium-low) SSP5: Fossil-fueled (high)

A1FI: Fossil intensive (high); A1B: Balanced energy (medium-high); A1T: Energy transition (low)

*Cumulative total $\mathrm{CO}_{2}$ emissions 1990-2100.

providing a more solid basis for complementary mitigation and adaptation analyses with the SSP/RCP (Riahi et al., 2017).

At one end of the emissions range, a family of optimistic scenarios explores worlds in which governments join forces, e.g., through adopting environmental or other sustainable development policies to promote global advances in low-carbon technologies. At the same time, poverty and inequality are reduced (Global sustainability). As further discussed below, IS92 and SRES explicitly exclude specific climate or mitigation policies because of their terms of reference (IPCC intergovernmental mandates) (IPCC, 1996; IPCC, 1991). At the other end of the emissions range, scenarios include rapid global economic growth based on fossil fuels and reduced inequality (rapid growth) or examine countries that upgrade their use of cheap fossil fuels, pursuing national economic growth (regional competition).

\subsection{Historical trends for emissions and main emissions drivers}

$\mathrm{CO}_{2}$ emissions from fossil fuels and industry grew by about $1800 \%$ between 1900 and 2018, with an average annual rate of $2.5 \%$. The yearly emissions growth during the IPCC period was $1.7 \%$.

In total, we find twelve sub-periods of higher and lower $\mathrm{CO}_{2}$ emission growth between 1960-2020 (including recent projections of 2019 and 2020) and seven subperiods between 1990-2020 (Fig. 1, Panel A). When we leave out very short-term events (1-2 years), we see that the entire period contains six periods of reversed higher and lower emissions growth. The IPCC period includes two high (1988-1991 and 1999-2012) and two medium-low growth sub-periods (1992-1998 and 2013-2020). Emission growth in the last decade is significantly below the long-term average.

In essence, the sub-periods since the establishment of IPCC (in 1988) show very different average annual growth rates, emphasizing the importance of distinguishing between short-term and long-term trends (van Vuuren et al., 2010). Since the emissions scenarios (and their models) do not capture short-term variability, but long-term developments (Manning et al., 2010; van Vuuren et al., 2010), it makes sense to evaluate the scenario projections against long-term historical developments.

Additionally, it is challenging to disentangle short-term influences (about five years) and long-term drivers (several decades or a century) influencing emissions. Our comparison of higher and lower emissions growth periods (Fig. 1 Panel B) illustrates that the average sub-period growth rates for $\mathrm{CO}_{2}$, GDP, and primary energy supply (PES) followed approximately similar higher and lower growth patterns until the
1992-1994 period. The 8-year moving averages show similar patterns for $\mathrm{CO}_{2}$ and energy, while population growth didn't correlate well with $\mathrm{CO}_{2}$ (see Fig. 2).

Financial crises do not appear to have had a lasting effect on global emissions. Interestingly, we see that GDP growth rates, after the 1992-1994 period, have been relatively stable with low variability between higher and lower emission growth periods. However, PES continues following the reverse in higher and lower emissions growth. As such, primary energy appears as a more reliant short-term indicator of emissions growth.

The latest period (2013-2018) has medium-low emissions combined with stable economic growth. The 2013-2016 drop marks a shift from historical patterns, showing a stationary situation or slower growth in emissions that was not forced by financial crises in major world regions like in $2008 / 2009,1998 / 1999$, and earlier. It may be a result of at least three fundamental changes: emerging climate policies (Burck et al., 2018; OECD, 2019), falling prices of renewable energy technologies (IRENA, 2019a; Observ'ER, 2019), and expansion of fracking ${ }^{5}$ (IEA, 2019b). The not yet estimated 2019 emission growth is expected to be low (0.6\%) (Friedlingstein et al., 2019), and a temporary drop between -4 and $-7 \%$ is expected for 2020 , due to the effect of the Covid-19 pandemic on economic activities (Le Quéré et al., 2020). It may lead to an overall growth rate of around $1.5 \%$ between 1990 and 2020. It is, however, too early to state the long-term consequences of the Covid-19 pandemic as well as plausible structural changes.

The share of fossil primary energy has remained almost unchanged, around $82 \%$, since 1990 . At the same time, total and fossil fuel primary energy supply have increased by $1.74 \%$ annually between 1990 and 2017 (IEA, 2019a), similar to the $1.70 \%$ annual $\mathrm{CO}_{2}$ emission increase (GCP, 2019). There is no convincing evidence yet that the world has already started a sustained global energy transition leading to decreasing fossil growth.

All examined emissions drivers have been continuously growing throughout the examined (and IPCC) period. However, our comparison of developments in interannual growth rates shows a different picture. As illustrated in Fig. 2, world population growth rates declined continuously. Global average GDP growth has stabilized with a small decrease, while $\mathrm{CO}_{2}$ and primary energy supply (PES) followed similar up and

\footnotetext{
5 On the contrary, although gas may be more efficient than coal, fracking may lead to methane emissions (Cremonese et al., 2019), which add increased complexity to the relationships between technology and greenhouse gas emissions and thus the models assessing societal impacts on emissions.
} 


\section{Box}

Key Scenario Narrative families

Developing the SA90 scenarios in the late 1980s, modelers made assumptions about possible future socioeconomic developments and their associated GHG emissions (Bolin, 2007; IPCC, 1990). The developers provided mainly narratives of lower, average, and higher economic growth and different climate policy levels. Scenarios involved one "baseline", one "low emissions", and two "intervention" scenarios (including mitigation policies). In the following sets, the emissions ranges were increased to include high-emission pathways, i.e., scenarios with high cumulative emissions trajectories (IPCC, 1991; Leggett et al., 1992; Nakicenovic and Swart, 2000). The second (IS92) and third (SRES) generation comprise only baseline and no intervention scenarios (Leggett et al., 1992; Nakicenovic and Swart, 2000).

In the first generation (SA90), elaboration of the regional level scenarios was less well developed (IPCC, 1990); thus, global (in-)equality considerations were less explicit. Inequality later became one of the governing principles of the SRES and SSP assumptions (Nakicenovic and Swart, 2000; O'Neill et al., 2014). The "rapid-growth" and "global-sustainability" families generally describe future worlds with increasing global equality. In general, they represent the highest and lowest cumulative emissions pathways, respectively (Nakicenovic and Swart, 2000; Riahi et al., 2017).

Global sustainability scenarios: The scenarios quantify a peak and decline in emissions from about $6 \mathrm{GtC} /$ year in 1990 to a range of 3-7 GtC/year by 2100 . They assume a shift in values from economic growth to sustainable development (e.g., climate or environmental policy assumptions). No intervention scenarios (climate policy assumptions) were included in IS92 and SRES. After the SA90s, policy assumptions were excluded in the IPCC mandate for IS92 (IPCC, 1991; Leggett et al., 1992) and SRES (IPCC, 1996; Nakicenovic and Swart, 2000). Thus both generations evolved in the absence of climate policy assumptions (Leggett et al., 1992; Nakicenovic and Swart, 2000). However, low emissions scenarios were included, based on other assumptions, such as side effects of non-climate/environmental policies (Alcamo et al., 1994) and technological development (Nakicenovic and Swart, 2000). Emissions by 2100 range from 3 to 7 GtC/year (Annual mean growth rates 1990-2100: -0.4 to $0.3 \%)$.

Regional sustainability: Scenarios in this family assume moderate technology innovation in high-income regions and quantify global slow emissions growth throughout the century. In these scenarios, emissions increase between 10 and $14 \mathrm{GtC}$ /year by 2100 (Annual mean growth rates: $0.6-0.7 \%)$.

Middle-of-the-road: These scenarios follow similar assumptions and medium-high emission pathways. The original Business-as-Usual (BaU) scenario in the SA90 was criticized at IPCC sessions, and thus this label was officially excluded in the successive scenario terminologies (IPCC, 1991). However, this type of scenario was represented in the IS92 via two scenarios (Leggett et al., 1992) and in the SSPs, labeled 'Middle-of-theroad'. The SRES set does not have such a scenario narrative. This family's scenarios increase from about $6 \mathrm{GtC} / \mathrm{year}$ in 1990 to about $20 \mathrm{GtC} /$ year in 2100 (Annual growth rates: $0.8-1.3 \%$ ).

Regional competition: In general, these scenarios assume low environmental regulation, high population, weak economic growth, and slow technological change. Three scenarios (SSP3, A2, and IS92f) fit this description best. They project an increase in the range of 22-28 GtC/year by 2100 (Annual growth rates: 1.2-1.7\%). One SSP scenario (SSP4) assumes continued global inequality with energy transitions in high-income regions, thus quantifying a peak-and-decline emissions pathway to $12 \mathrm{GtC} /$ year by 2100 (Annual growth rates: $0.7 \%$ ).

Rapid growth: These scenarios assume rapid economic growth. In most rapid growth scenarios, growth is provided via a fossil-fuel intensive energy sector and quantifies emissions in the range of 30-35 GtC/year by 2100 (Annual growth rates: 1.5-1.8\%). As mentioned earlier, two of the SRES rapid-growth scenarios quantify high economic growth but medium-high and low cumulative emissions because of various degrees of energy transitions. They quantify annual mean growth rates in the range of -0.3 to $0.7 \%$.

\section{down patterns.}

In conclusion, the historical shifts in emissions trends (GCP, 2019) makes it difficult to interpret trends based on a couple of years (Manning et al., 2010; van Vuuren et al., 2010), which has been done in the literature before (Raupach et al., 2007). In this context, we evaluate the historical and current emission pathway compared to, and in the light of, the following scenario sets used to inform IPCC assessment reports.

\subsection{Emissions scenarios against historical trends}

During the period analyzed, historical global emissions generally developed within the range of pathways described by the IS92, SRES, and SSP-BL sets. Emissions exceeded the SA90 range post-2000 (Fig. 3). However, our 1985-2020 period's assessment shows that the SA90 middle-of-the-road projects an emissions growth (1.7\%) lower than the historical trend for the same period (1.8\%).

We locate an emission trajectory similar to scenarios that project a medium-high century-long emissions pathway for the examined period. Middle-of-the-road scenarios best capture this. Considering the projected emissions growth in 2019 (0.6\%) (Friedlingstein et al., 2019), current emissions are close to middle-of-the-road, global sustainability, and the SRES rapid-growth technology transition scenario assuming high non-fossil energy transition.

The historical emissions trajectory followed a low to medium-low to medium-high emissions pathway between 1992 and 1998, which was similar to the middle-of-the-road scenarios, as well as SRES and SSP global-sustainability scenarios. Between 1999 and 2012, emissions followed a trajectory between medium-high and high emission pathways, which was between IS92 middle-of-the-road and regional-competition scenarios. From 2013 to 2016, historical growth was below 1\% annually, which made the observed $\mathrm{CO}_{2}$ emissions pathway return to the center of the ranges of the scenario sets - back to being close to middleof-the-road and global-sustainability scenarios.

We note that the lower ends of the scenario ranges have moved up and not down - for the successive sets. This may be because the later sets accounted for the realized emissions, and the fact that SA90 was the only set including "marker" scenarios with explicit policy. The differences in the uncertainty emissions range between the scenario sets are to be expected. The SA90 has a broader uncertainty range since it projects a more extended period (33 years) and includes mitigation scenarios. We note that, in general, the uncertainty range has declined depending on the number of years they cover with IS92 (covering 28 years), SRES (20 years), and SSP (15 years). However, the uncertainty range for SA90 is lower due to the more 'positive' projections (not including highemission scenarios). 


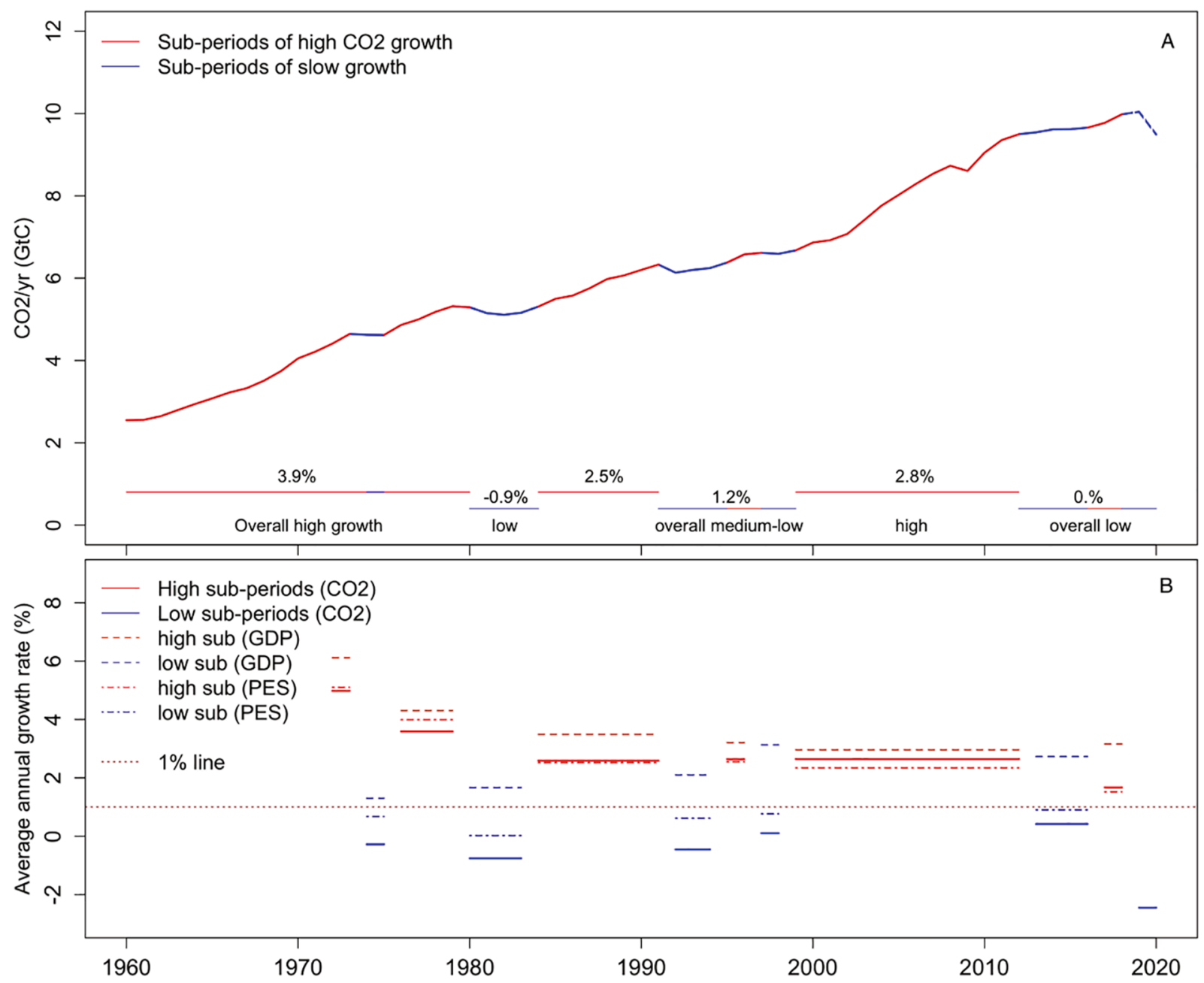

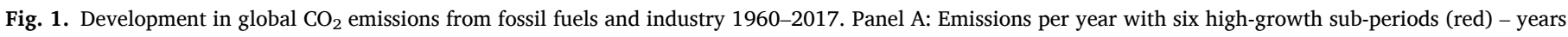

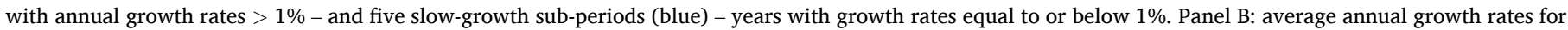

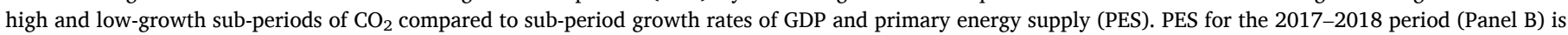

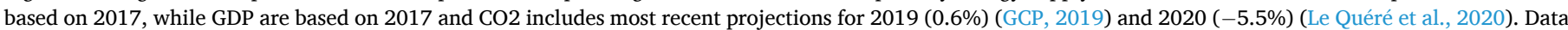

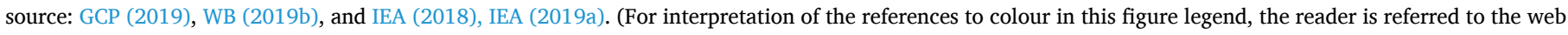
version of this article.)

\subsection{Emissions and socioeconomic scenarios against the historical trend}

The actual global development in $\mathrm{CO}_{2}$ from fossil fuels \& industry and the four key emissions drivers examined during the past three decades are, in general, quite close to the middle-of-the-road scenarios in the IS92 set. For the SRES and SSP sets, it looks different. Here globalsustainability scenarios are comparable to emissions growth and the most direct driver, fossil primary energy growth (Fig. 4).

Historical energy and economic growth are best captured by IS 92 "middle-of-the-road" and "regional-sustainability", while SRES "global-" and "regional-sustainability" are close. SSP "middle-of-the-road" and "global-sustainably" are below but most comparable to historical energy growth.

In essence, the scenarios compare well with the historical trends for underlying variables for the global population, GDP, and PES. There are two exceptions: the SSP population and GDP growth, where historical increases are above and below scenario ranges, respectively. Although historical population growth was below the SSP-BL range, the global historical trend is still within the United Nations population scenario range (United Nations Statistics Division, 2020). When including the entire SSP range (including the SSP mitigation scenarios), historical population growth is well within the SSP range. The historical GDP growth is within the SSP range, considering the 1990-2020-period, while historical population growth is still above the SSP-BL range.

\subsection{Non-fossil energy scenarios}

Historically, both fossil and non-fossil energy grew by $1.7 \%$ per year between 1990 and 2017.

During this period, the IS92 set projected a non-fossil growth (2.8-4.9\%) higher than the actual historical developments, while SRES $(1.7-3.9 \%)$ almost also did the same (Fig. 5). The SSP-BL range $(0.8-2.7 \%)$ was consistent with the historical growth trend between 2005 and 2017 (1.8\%).

Exploring the three sub-categories of non-fossil primary energy, it appears as if nuclear energy has decreased faster than expected in most scenarios, thus further analyses of trends, outlooks, and energy policies are recommended to evaluate if there is a need for adjusted nuclear energy assumptions in future scenario updates. This depends on factors such as the Post-Paris Agreement negotiations and the future role of nuclear in policies, which is still unclear.

Additionally, it is too early to state if there are reasons to adjust SSPBL "non-biomass renewables" assumptions. Renewable energy is maturing quickly and is becoming price competitive with fossil fuels in 
Population
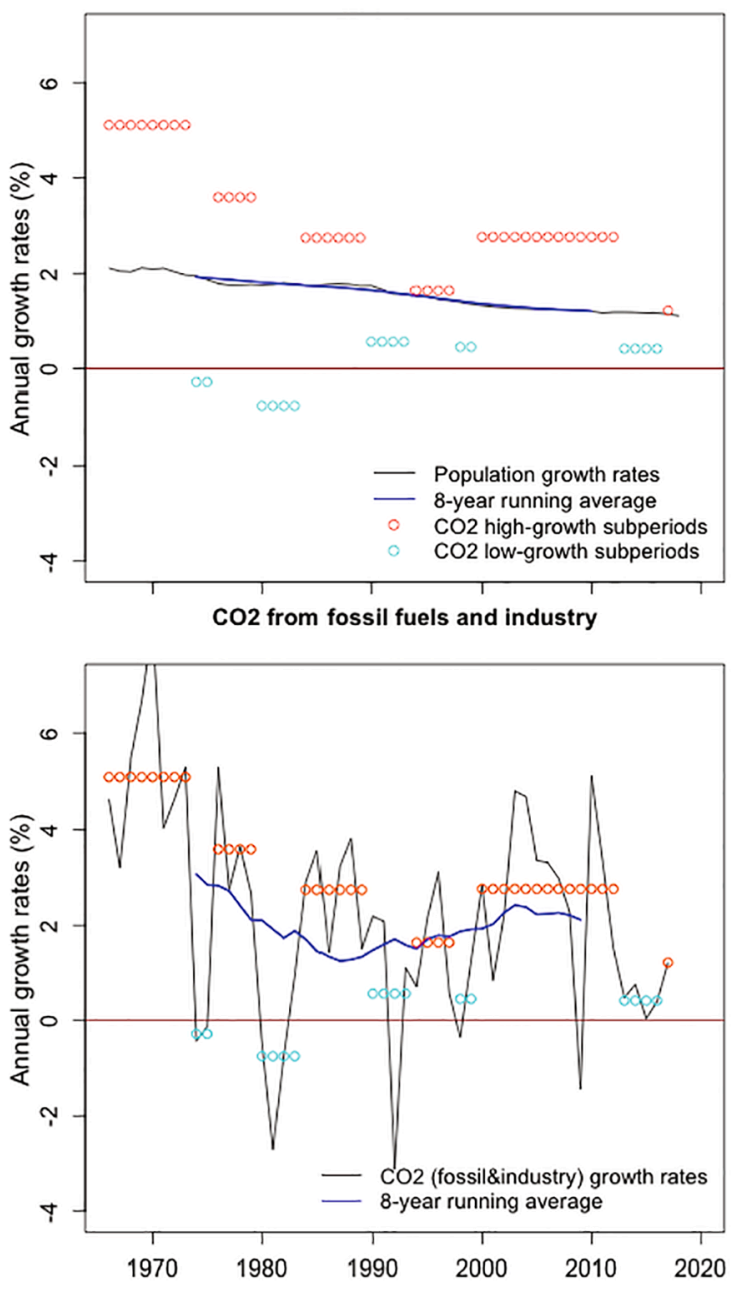

GDP MER

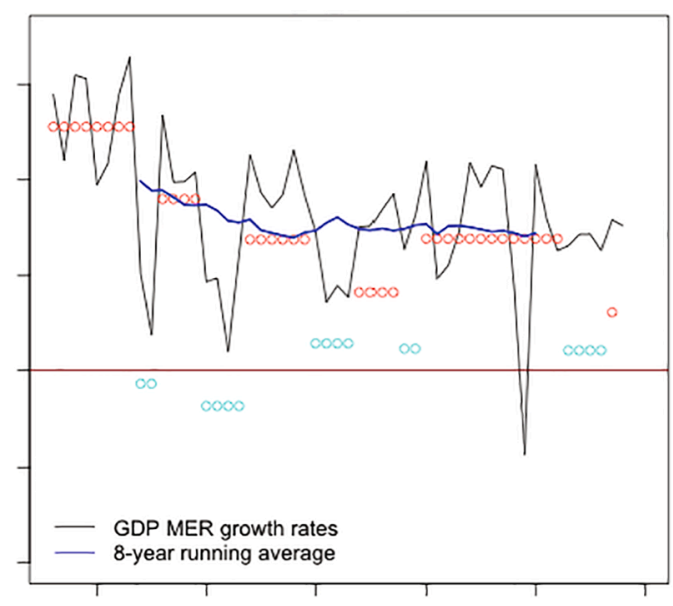

Primary energy supply (PES) and consumption (PEC)

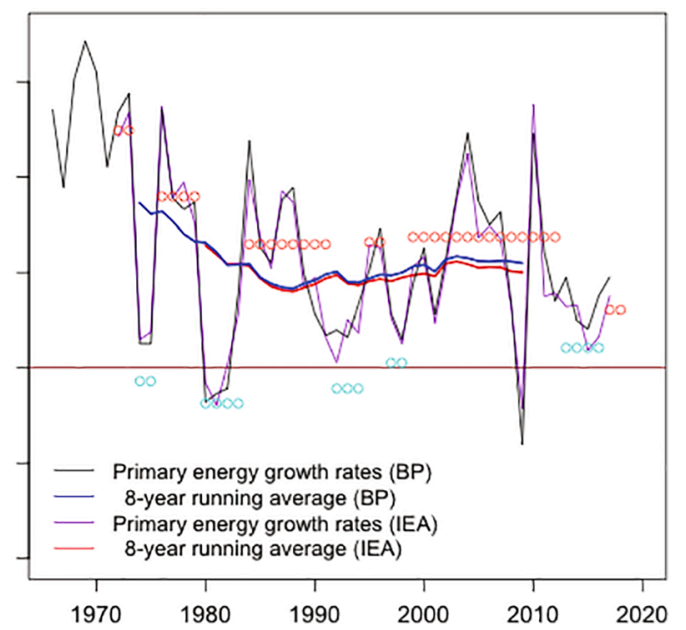

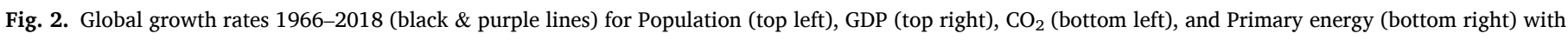

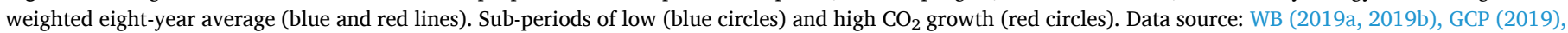
IEA (2018), and BP (2018). (For interpretation of the references to colour in this figure legend, the reader is referred to the web version of this article.)

several regions (IRENA, 2019b; Metayer et al., 2015; Observ'ER, 2019). They may be ready to play a defining role in a near-term future promoted by climate policies and market forces. Such developments may indicate that renewable energy scenarios could move in a different direction than expected in the SSP-BLs. ${ }^{6}$

\subsection{Non-OECD and OECD scenarios}

IS92, and SRES scenarios underestimated emissions growth in nonOECD countries, and emissions track the high end of the SSP range. The opposite counts for OECD countries, where historical emissions follow the low end of IS92 and are below SRES and SSP ranges (Fig. 6).

In general, "rapid-growth" and "regional-competition" scenarios have

\footnotetext{
${ }^{6}$ Here it also depends on other factors, such as G20 energy investments in low-income regions (Doukas et al., 2017), insurance, and lending policies (Farand, 2019), as well as development in energy subsidies (Coady et al., 2017). Additionally, the public debate is now focusing increasingly on mitigation (Henley, 2019; Levitz, 2018), while historical opponents of climate change science and policy (Flannery, 1985; Reheis-Boyd, 2014) are now promoting themselves as climate responsible (Clinton, 2017; ExxonMobil, 2018). However, the US withdrawal from the Paris Agreement and the consequences of the COVID-19 pandemic will affect energy investments, but it is difficult to see in which direction (Le Quéré et al., 2020; Tollefson, 2020).
}

been closest to the historical non-OECD emissions and energy trends. In contrast "global-sustainability" scenarios were close to those of the OECD. Historical population growth in non-OECD track middle of scenario ranges, while OECD tracked high-end and almost higher than projected. We note that the SSP range for non-OECD was above historical GDP 2005-2017 and the SSP OECD range below. Additionally, historical total and fossil primary energy growth track the low ends of SSP ranges. The SSP3 "regional-competition" scenario was close to nonOECD fossil energy and emissions variables, while the SSP1 "globalsustainability" scenario was, in general, equivalent to OECD total and fossil energy variables.

Overall, the four sets capture the direction of global socioeconomic development well. In particular, the IS92 and SSP middle-of-the-road, and the SSP and SRES global sustainability scenario were quite precise in global emissions and energy scenarios. Since there are still two to three more years of the various annual estimates to calculate complete growth rates for the 1990-2020 period, changes may happen. A drop in annual 2020 emissions, given the impact of the Covid-19 pandemic (Le Quéré et al., 2020), may lead to lower overall historical growth estimates.

\section{Discussion}

Climate change extends far into the future, making emissions 


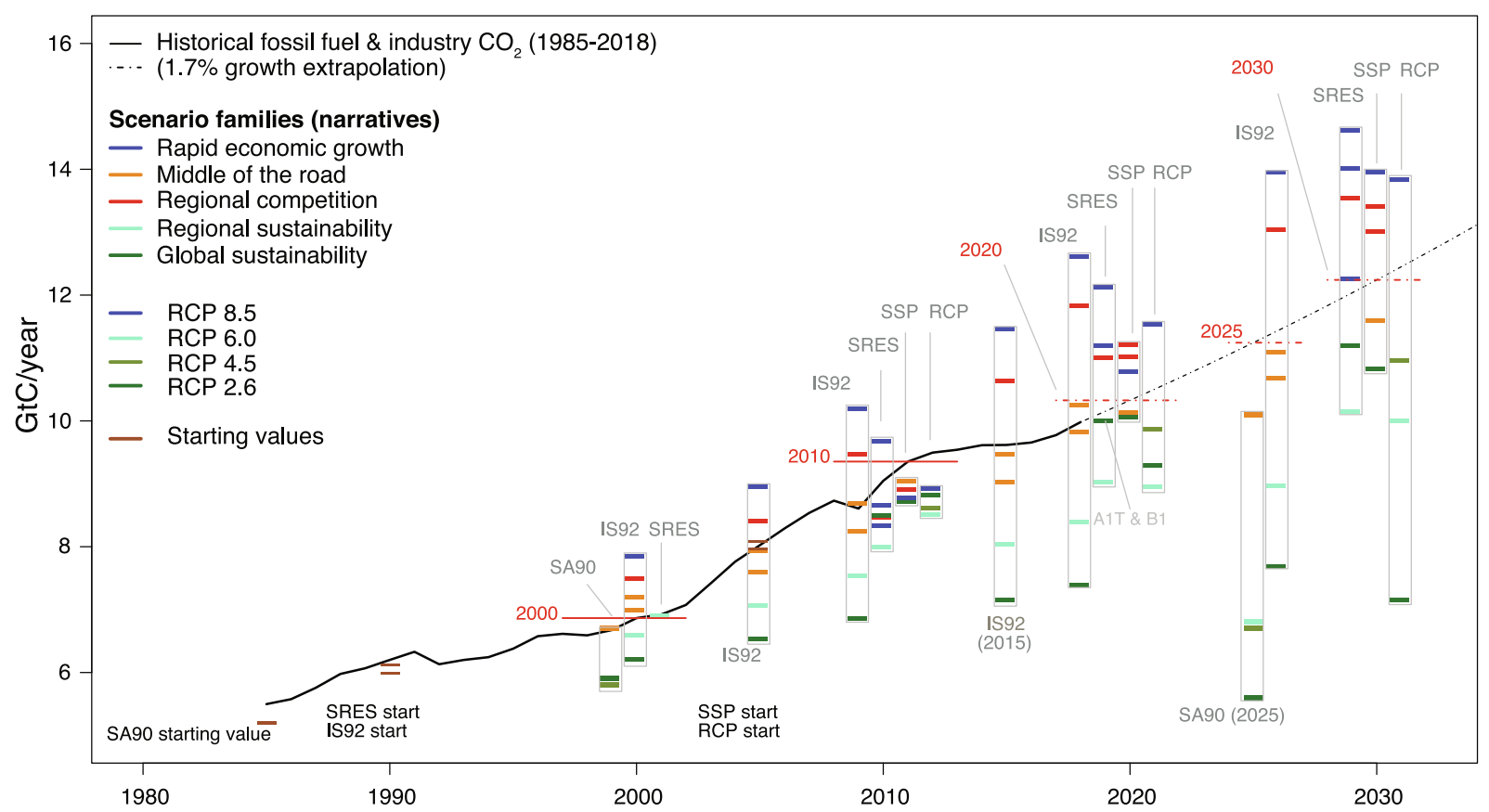

Fig. 3. Observed $\mathrm{CO}_{2}$ emissions trend over the past three decades (black line) compared with emission scenarios SA90, IS92, SRES, RCPs, and SSP-BL. The black dotted line shows extrapolation beyond 2018 of the 1.7\% growth rates for 1990-2018 historical emissions. 'Rapid growth' (includes IS92e/SRES-A1B/SSP5), 'Middle of the road' (SA90-A/IS92a/b/SSP2), 'Regional competition' (IS92f/SRES-A2/SSP3/SSP4), 'Regional sustainability' (SA90-B/IS92d/SRES-B2), 'Global sustainability' (SA90-C/D/IS92c/SRES-B1/SSP1). Data sources: IPCC (1990), Pepper et al. (1992), Nakicenovic \& Swart (2000), Riahi et al. (2017), van Vuuren et al. (2011), GCP (2019).
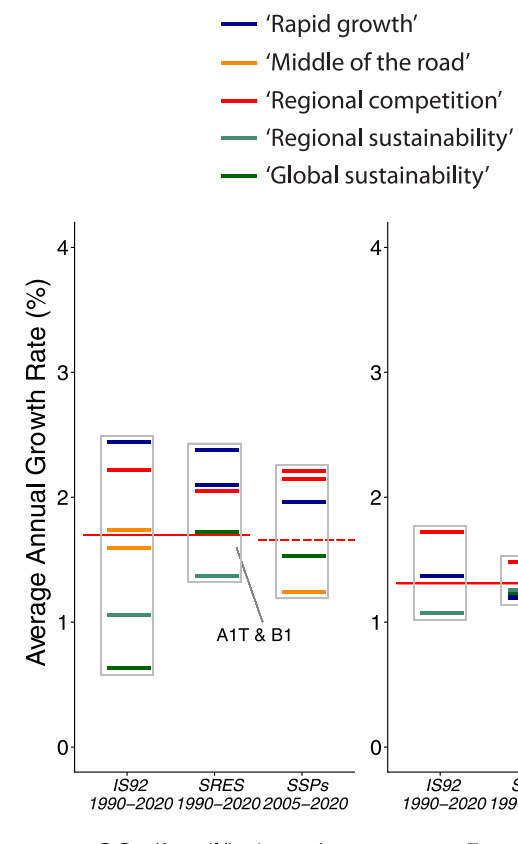

$\mathrm{CO}_{2}$ (fossil/industry)

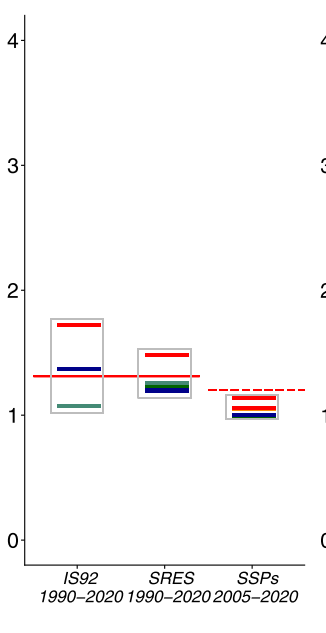

Population

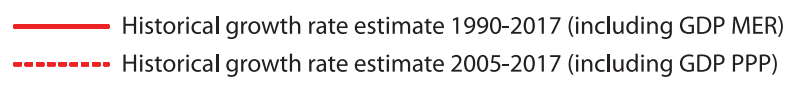

Historical growth rate estimate 2005-2017 (including GDP PPP)
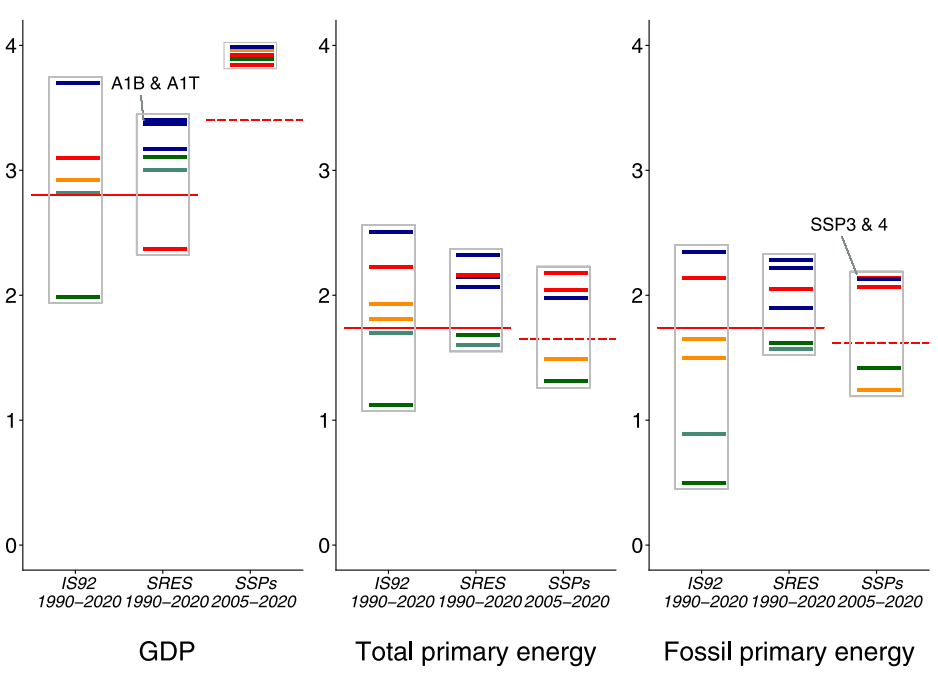

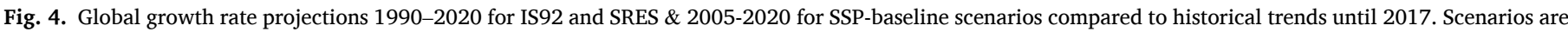

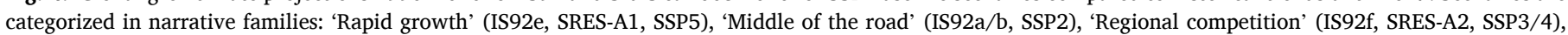

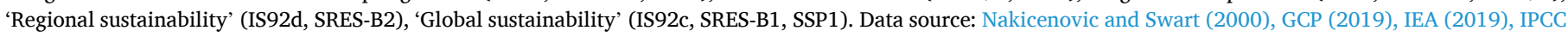
(1990), Pepper et al. (1992), Riahi et al. (2017), WB (2019a, 2019b, 2019c).

scenarios and associated development in emissions and drivers essential for a broad range of analyses of climatic change mitigation, impacts, and adaptation. Regular evaluations of these scenarios are crucial, as new information about technological and socioeconomic developments becomes available over time, and scenario methods and tools change
(Allen, 2003; O'Neill and Schweizer, 2013; van Vuuren et al., 2010). This paper compares observed emission trends with emission scenarios over a more extended period than has been done before and addresses the performance of subsequent sets of scenarios developed for IPCC assessment. 


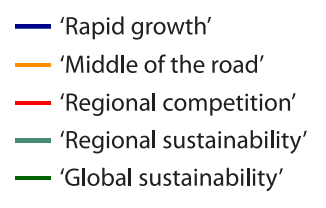

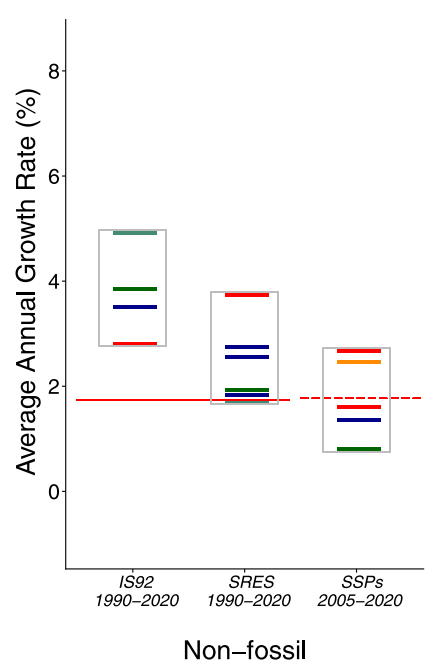
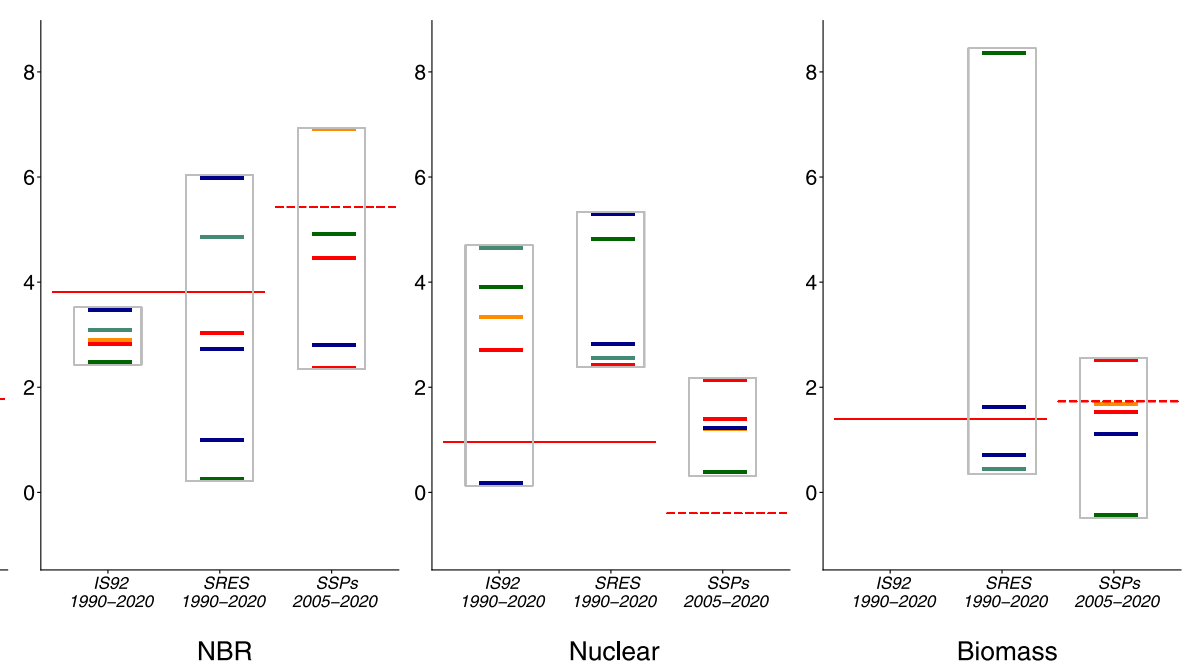

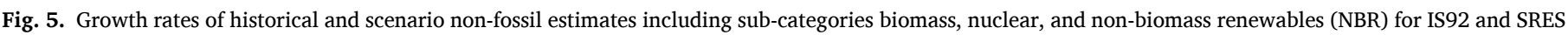

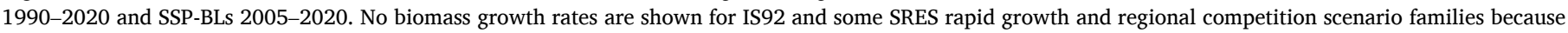
their 1990-estimates were zero. Data source: (1990), Nakicenovic and Swart (2000), IEA (2019), Pepper et al. (1992), Riahi et al. (2017).

Since a complete assessment of all variables would exceed one paper's scope, we focused on the most critical greenhouse gas emissions $\left(\mathrm{CO}_{2}\right.$ from energy and industry) and the central drivers.

Overall, our analysis shows that long-term global emission development is relatively close to the middle of the scenario ranges. Still, some significant deviations were noted for indicators at a more detailed level. Below, we briefly discuss some of the results.

\subsection{How do the projected emissions hold up against historical trends?}

During the various periods of relatively rapid or slow growth, the emissions scenarios were critiqued in the literature as having either an upward bias in emissions projections (Castles and Henderson, 2003b; Gray, 1998) or a downward bias (Le Quéré et al., 2009; Peters et al., 2013; Raupach et al., 2007). However, we note that sub-periods of high and low emissions growth have counterbalanced each other in the past, keeping the long-term trend well within the ranges of IS92, SRES, and SSP-BL sets. All in all, there is very little support for earlier claims that future emissions would be systematically overestimated at the global level, except for the 1st set (SA90). In a century-long window, the highest SA90, the SA90-A "middle-of-the-road" scenario, has slightly higher emissions growth projections (1.3\%) than its equivalent middleof-the-road scenarios in the IS92s (1.1\%) and SSP-BLs (1.2\%) (Leggett et al., 1992; Riahi et al., 2017). Whether the relatively good correlation between medium scenarios and the historical data will also continue in the future is uncertain. Global emission growth between 2010 and 2018 is significantly below the long-term average, and as a result, the trend during this period is at the low end of the SSP-BL range. In 2019 emission growth was low $(0.6 \%)$ (GCP, 2019), and a temporary drop is expected for 2020 due to the effect of the Covid-19 pandemic on economic activities (Le Quéré et al., 2020).

\subsection{Differences between $O E C D$ and non-OECD regions}

Our results suggest that the emissions scenario sets capture fairly well global socioeconomic developments but show differences notably for regional projections. The magnitude of non-OECD emissions and fossil primary energy growth 1990-2017 is higher than in the IS92 and SRES sets. There could be several reasons for this, including higher economic growth in non-OECD countries and/or a shift stronger than expected of industrial activity from OECD to non-OECD countries. In this context, it should be noted that the choice of the accounting method for greenhouse gas emissions can have fundamental effects. Following international rules, the assumptions for all emission scenario sets were developed to track emissions within national territories (Leggett et al., 1992; Nakicenovic and Swart, 2000; Riahi et al., 2017), rather than emissions related to consumption (Peters et al., 2012). ${ }^{7}$ Fig. 7 illustrates how OECD consumption-related emissions are significantly higher than their territorial, production-related emissions.

Emissions from the manufacture of traded goods and services are increasing, leading to rising shares of global $\mathrm{CO}_{2}$ from producing countries (Peters et al., 2012), particularly China and India. In contrast, EU-28 and North America "consume more than they produce" in terms of emissions (GCP, 2019) - consumption-related emissions per capita for the US and EU-28 are 1.3 and $1.4 \mathrm{tCO}_{2}$ /person higher, respectively, compared to their terrestrial production-related emissions (calculations are based on data from GCP, 2019; WB, 2019a). The scenario studies do not explicitly deal with trade (other than energy carriers) (O'Neill et al., 2017; Riahi et al., 2017). Arguably, the scenarios indirectly, or implicitly, include shifts in production from OECD to non-OECD regions, via the calibration to historical trends (before publication year of the scenario sets) and the underlying assumptions for regional developments. As a result, it is challenging to assess whether the shifting industrial activity is the leading cause of the growth in non-OECD countries being more rapid than projected (Pedersen et al., 2020). Nevertheless, under international rules, emissions from production in one region to satisfy consumption in another remain attributed to the producing regions.

Our analyzes provide evidence that, in particular, the earlier

\footnotetext{
${ }^{7}$ Although International trade has guided some SSP assumptions regarding land-use (Riahi et al., 2017) and market regulations related to economic growth and technology developments (O'Neill et al., 2017), consumption emissions were not included. Thus, there is no fundamental change in the assumptions or models across the sets regarding national inventories.
} 

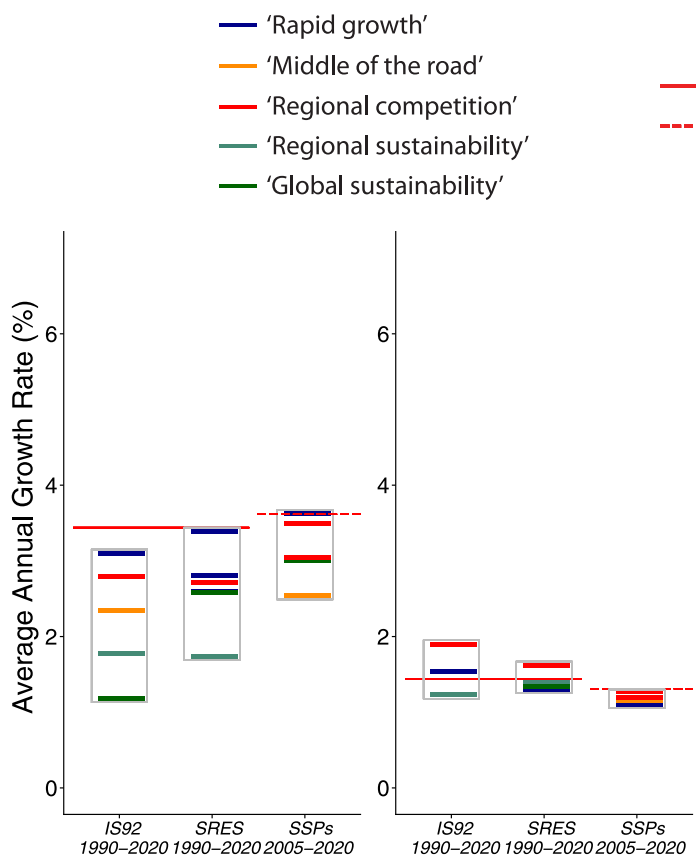

$\mathrm{CO}_{2}$ (non-OECD)

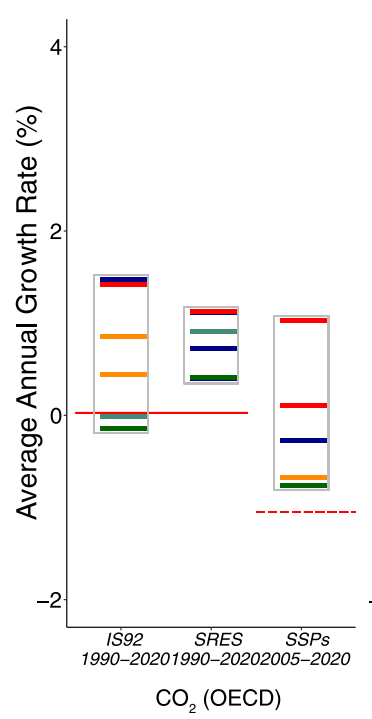

Population (non-OECD)

0
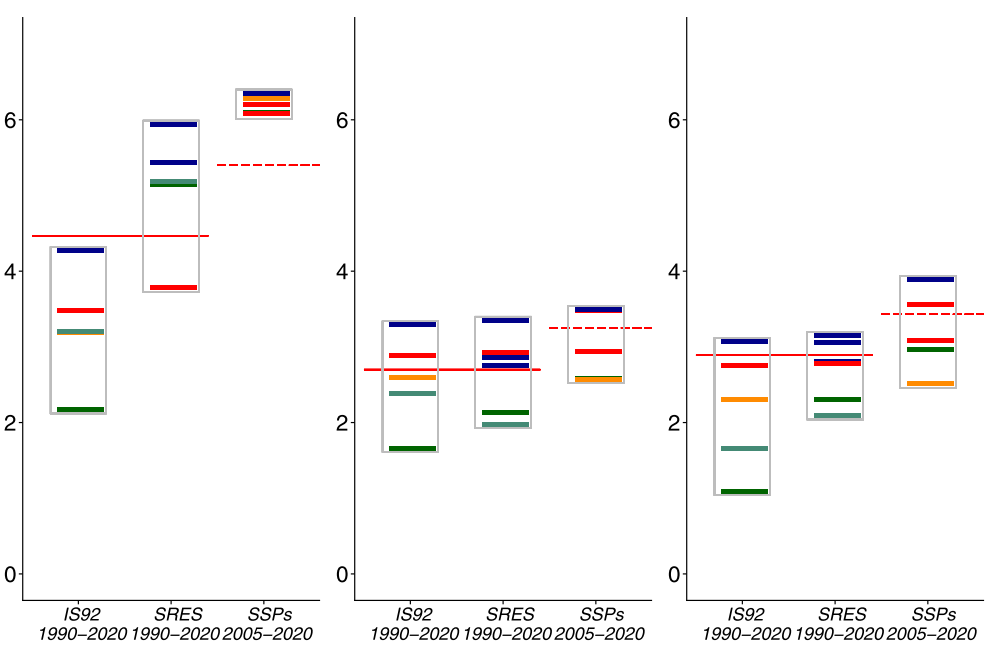

GDP (non-OECD)

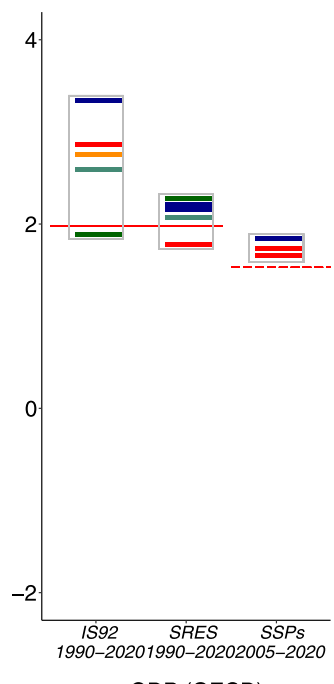

GDP (OECD)
Total PES (non-OECD)

Fossil PES (non-OECD)
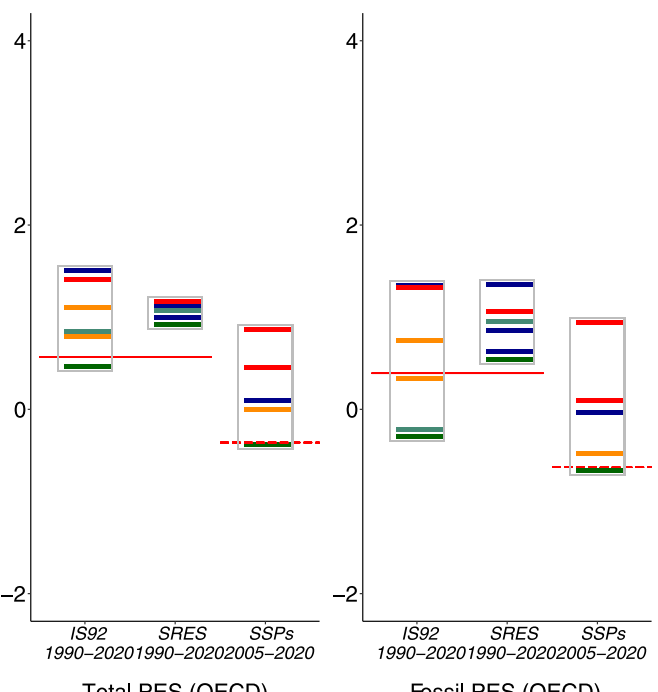

Total PES (OECD)

Fossil PES (OECD)

Fig. 6. Non-OECD and OECD growth rates of historical and scenario CO2 emissions (fossil fuels and industry), population, GDP, total primary energy, and fossil primary energy 1990-2020. Top panel: non-OECD. Bottom panel: OECD. The definitions of OECD and non-OECD differ between the IS92/SRES and SSP databases (e. g., IS92/SRES OECD is based on "OECD90" and thus including fewer countries than the SSP OECD category including "OECD90 + EU member states and candidates"). Historical estimates were calculated according to SSP definitions and IS92 definitions for emissions, population, and GDP. The representation of countries in the energy database was considered too small, and thus the IEA database definition was used. Data source: Nakicenovic and Swart (2000), GCP (2019), IEA (2019), Pepper et al. (1992), Riahi et al. (2017), WB (2019a, 2019b, 2019c).

scenarios captured regional trends less well but did not reveal the causes behind that. There is no evidence of potential regional modeling bias. Still, the results may put a new focus on the significance of considering a broad set of issues determining future developments, also beyond the processes and indicators included in the models used. Potential regional biases in scenario development (such as a biased 'northern' perspective) have been widely discussed in the literature (Parikh, 1992; Shukla, 2004) and in and IPCC sessions (IPCC, 2006; 1996). These also include arguments to include more 'developing' country expertise. This has shaped the SRES' terms of reference (IPCC, 1996; Nakicenovic and Swart, 2000) and inspired the RCP/SSP development principles (IPCC, 2006; 2005). Different stakeholders have been included in scenario preparations and discussions, contributing to diverse perspectives
(IPCC, 2007a; 2005). In essence, it appears increasingly essential to intensify knowledge about socioeconomic developments, the functionality of institutions, and policy implementation in non-OECD countries (Ajulor, 2018), because it is very different from those in many highincome countries from which region the models originated. This appears essential both to strengthen future scenarios and to inform future climate change response choices.

\subsection{Representation of income variables}

Changes in indicator characteristics, like their definition or choice of units, may affect projections. In the SA90, IS92, and SRES, economic growth was reported in US dollars based on conversions using market- 


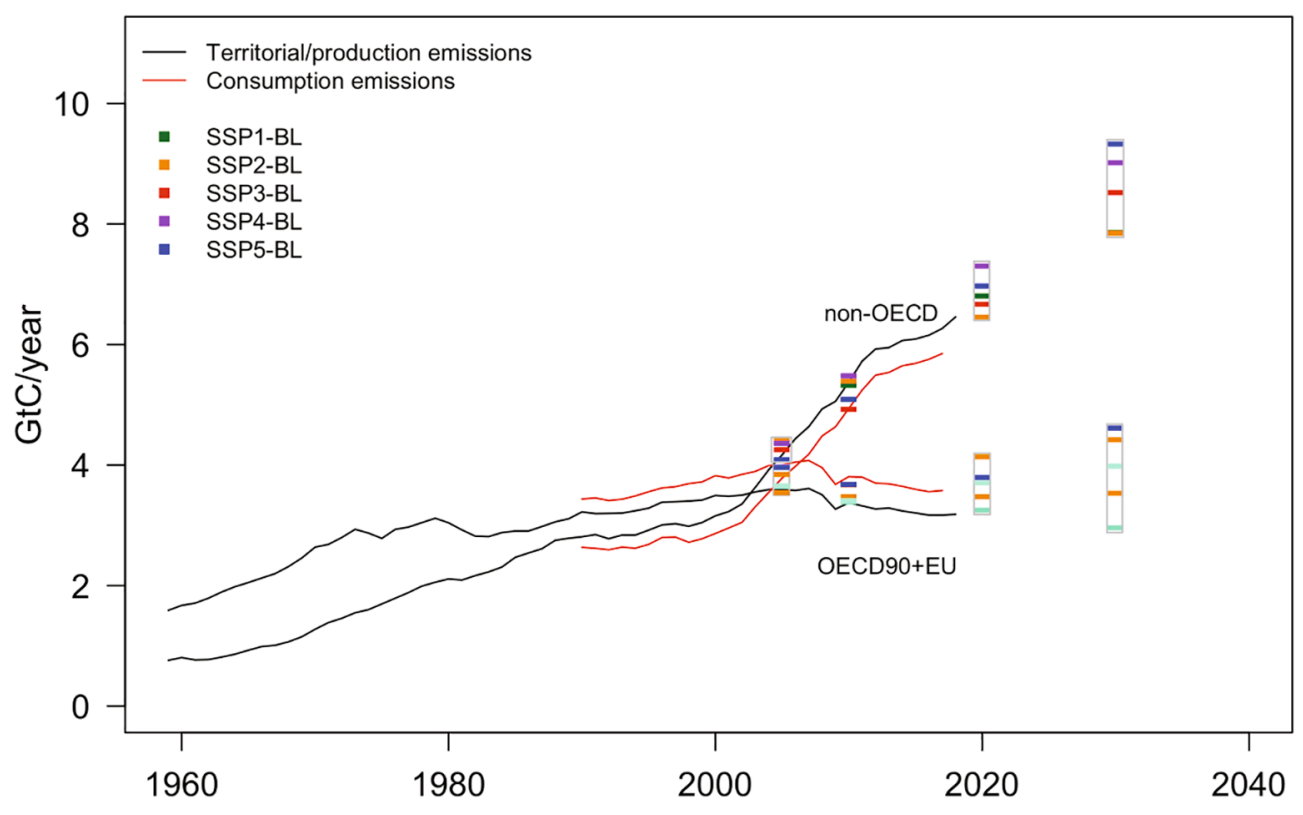

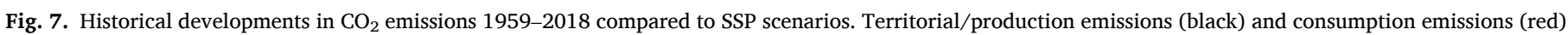

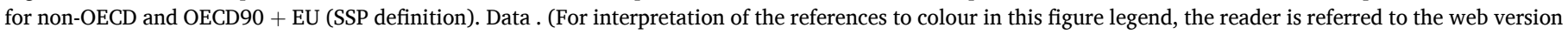
of this article.)

Source: GCP (2019), Riahi et al. (2017)

exchange rates (MER). The SSPs use purchasing power parity (PPP). As a consequence of the choice of indicator, the SRES was critiqued for overestimating economic growth and, therefore, also emissions growth in the "rapid-growth" and "global-sustainability" families (Castles and Henderson, 2003a; 2003b; 2005; Henderson, 2006). The critique was picked up by both governmental (Tol, 2005) and media debates (The Economist, 2003), although hardly any useful PPP-based databases (WB, 2019) nor PPP-based analyzes existed at the time that could have been used in the SRES models (IPCC, 2007b). The critics (Castles and Henderson, 2003b) argued that PPP compares the actual welfare levels across regions more accurately (Holtsmark and Alfsen, 2005; Van Vuuren and Alfsen, 2006). They stated that using MER to reach global economic convergence would lead to overstated economic growth projections in low-income regions. In their opinion, this would result in disproportionate aggregated growth in energy demand and emission levels, which would not represent the actual high and low end of the emissions range in a reliable manner (Castles and Henderson, 2003a; 2003b). Our results show that the emission growth in the SRES scenarios was lower than the historical data for the non-OECD, but this is not the case for economic growth. Comparing MER and PPP growth rates for the 1990-2018 period, global growth measured in PPP (3.4\%) is higher compared to MER (2.8\%). This is because of a rapidly growing GDP in low-income regions and the higher difference between MER and PPP metrics in low-income countries, compared to most OECD countries. For regional growth, the differences are, by definition, smaller.

While the critique itself (Castles and Henderson, 2003a) was not peer-reviewed, it initiated a heated debate (IPCC, 2007b; Montague, 2018; Van Vuuren and Alfsen, 2006). Research showed that differences between these two methods did not significantly affect emissions projections (Holtsmark and Alfsen, 2005; Manne et al., 2005; Van Vuuren and Alfsen, 2006). One critic accepted that his analysis was wrong (Montague, 2018).

\subsection{Limitations of models}

In essence, the "performance" of the scenario sets, compared with actual emissions at the global level, is within the ranges. But does this automatically mean that this will also be the case in the future? One can be right for the wrong reasons (equifinality). Furthermore, the future is unknown, and societal changes can happen unexpectedly, most recently exemplified by the Covid-19 pandemic. Additionally, the assessment in this paper focuses on key input and output of emissions scenarios. An analysis focusing more directly on performance and differences of the models used may provide other perspectives and suggestions for future improvements, complementing the presented results. The models can be right for high-level quantitative indicators, but this does not mean that they correctly capture the underlying story.

Our assessment of inputs and outputs of emission scenarios shows a high correlation between historical emission development and the scenario studies' medium values. In this context, we note that the IS92 set also captures global trends reasonably well. However, there was considerably less experience in modeling and scenario development at the time, and only a few modeling teams participated in the scenario development activities. At the same time, projections have become arguably more difficult given the gradual emergence of an additional factor, namely climate policy. This also means that even though the sets generally capture historical developments, this gives little proof of equally strong performance in the future.

Nevertheless, we note that scenarios were never meant to predict future trends, but rather to explore different possible outcomes. In that sense, all models have limitations - they cannot represent all possible quantified outcomes of a scenario narrative (IPCC, 2014a, 2007a) because they are 'idealizations' or 'simplification' of reality. They use current knowledge and scientific data; however, as knowledge progresses and more scientific data becomes progressively available, the models based on that knowledge and data are subject to change.

\section{Conclusions}

Due to the high relevance of emission scenarios as input for future climate change analyses that informed and shaped IPCC assessments for 30 years, it is relevant to regularly reassess the scenarios to inform future scenario development and the policy debate. Focusing on key variables $\left(\mathrm{CO}_{2}\right.$ from energy and industry, population, GDP, energy system characteristics), we have compared long-term historical developments of key socioeconomic drivers and greenhouse gas emissions and compared 
historical trends against scenario projections from 1990 to the present.

Our results show that the scenarios did not systematically overestimate or underestimate actual global emissions, as suggested earlier in the literature. History shows that it has been difficult to foresee shifts between and magnitude of "medium-low" and "high" emissions periods. The global historical emission trajectory was close to high-emissions scenarios from 1999 to 2012, which led to critiques in the literature and policy discussions, arguing that the upper scenario ranges were too low. Between 1990 and 1998 and 2013-2019, historical emissions were close to medium-high emissions trajectories. Over the period 1960-2020 (1990-2020), we identified twelve (seven) sub-periods of lower and higher growth (short-term periods). It illustrates that it is difficult to interpret trends based on a limited number of years of data. Good practice requires a distinction between long-term and short-term trends.

Overall, historical global emissions followed a medium-high emissions pathway for the three latest sets (IS92, SRES, RCP/SSP), well within those scenario ranges, however just above the highest emission scenario of the first set (SA90). Historically, $\mathrm{CO}_{2}$ emissions are tightly coupled directly with primary energy use, and indirectly with GDP: despite short-term variabilities in global $\mathrm{CO}_{2}$ emissions are mainly caused by a combination of slow changes in long-term drivers.

Most scenarios overestimated OECD $\mathrm{CO}_{2}$ emissions growth but underestimated non-OECD $\mathrm{CO}_{2}$ emissions. The SSP-BLs overestimated OECD GDP and underestimated non-OECD GDP growth and was at the margins of primary energy growth for both regions. The past global developments result from a combination of contrasting storylines in different areas at different times, such as the relatively low economic and emissions growth in the OECD region and higher growth in the nonOECD region, notably China and India. This can have implications for present policymaking and possible improvement of assumptions regarding the "outsourcing" or export of emissions in future scenario exercises, e.g., a plausibly renewed focus on consumption emissions and national responsibilities in an international policy context.

\subsection{Recommendations for future work in the area of global emission scenarios}

First, the recent development of national and international climate policy makes it increasingly problematic to compare the IPCC scenarios (which did not include climate policy by definition) with historical trends. However, we recommend that they can still be relevant as counterfactual baselines for climate change, impact, or response analysis.

Second, because the implementation of climate policies related to the Paris Agreement of 2015 may mean an active break with past trends, exploring policy options in further work on the latest scenario set (SSPs) in a long-term perspective becomes increasingly relevant. Third, it may be worthwhile to analyze discontinuous futures related to historical and future crises (as illustrated by the current Covid-19 situation) and possible societal transformations, which have not been addressed explicitly in any of the scenario sets used. Fourth, our analyses lead to the recommendation to re-evaluate SSP assumptions on particular developments in "non-biomass renewables" and "nuclear" primary energy - to judge if associated scenario adjustments would be desirable in future updates. Fifth, the fast-growing emissions in non-OECD regions provide a reminder that non-OECD emissions and outsourcing of emissions may play an increasingly important role in the global emissions, an issue very relevant for future policy choices and scenario development. Technically, it may be pertinent to consider more specific regions other than non-OECD/OECD or non-Annex/Annex1. These regions now include both high-income and low-income countries, different from the times that the first scenario sets were developed. Sixth, in the research underlying this paper, we focused on the emission scenarios and their drivers, not on the characteristics of the integrated assessment models used to quantify the storylines. Future research could evaluate to what extent these models are (still) suitable to assess the relationship between emissions and their socioeconomic drivers in a comprehensive and meaningful way. Seventh, future scenario work is recommended to include evaluating the total lifecycle emissions of large-scale application of new wind, solar, biomass energy technologies, fracking (including methane leakage), and land-use change.

\section{CRediT authorship contribution statement}

Jiesper Tristan Strandsbjerg Pedersen: Conceptualization, Formal analysis, Methodology, Writing - original draft, Software, Visualization, Project administration, Validation. Filipe Duarte Santos: Conceptualization, Resources, Supervision, Validation. Detlef Vuuren: Conceptualization, Methodology, Validation. Joyeeta Gupta: Supervision. Ricardo Encarnação Coelho: Investigation, Validation. Bruno A. Aparício: Software, Visualization. Rob Swart: Conceptualization, Methodology, Formal analysis, Methodology, Supervision, Validation.

\section{Declaration of Competing Interest}

The authors declare that they have no known competing financial interests or personal relationships that could have appeared to influence the work reported in this paper.

\section{Acknowledgments}

A special thanks to William Pepper (involved in IS92 and SRES developments) for a proof-reading paper review (including a valuable and low-cost language revision), and additionally, for scanning and putting a long lost IS92 report into circulation in the scientific community (available at ResearchGate). The authors would like to thank Paul Chakroff (University of Lisbon) for valuable language review and terminology support, and Andre Oliveira (Climate Change Impacts, Adaptation, and Modelling - CCIAM, University of Lisbon) for general positive, constructive, and productive inputs (including changing towards a more plant-based diet). Joyeeta Gupta acknowledges support from the "Netherlands Organisation for Scientific Research" (NWO) [project number W07.303.104] and the "Governance and Inclusive Development Group" of the University of Amsterdam in conducting this research. Jiesper Pedersen acknowledges support from "ANTHS - Innovation Anthropology" (Denmark) and the research unit "CCIAM-cE3c", University of Lisbon (Portugal).

\section{Appendix A. Supplementary data}

Supplementary data to this article can be found online at https://doi. org/10.1016/j.gloenvcha.2020.102199.

\section{References}

Ajulor, O.V., 2018. The challenges of policy implementation in africa and sustainable development goals. PEOPLE: Int. J. Soc. Sci. 3, 1497-1518.

Alcamo, J., Bouwman, A., Edmonds, J., Grubler, A., Morita, T., Sugandhy, A., 1994. An evaluation of the IPCC IS92 emission scenarios. Climate Change 1994 Radiative Forcing of Climate Change and an Evaluation of the IPCC 1992 IS92 Emission Scenarios. Intergovernmental Panel on Climate Change. Cambridge University Press, Cambridge, UK.

Allen, M.R., 2003. Climate forecasting: Possible or probable? Nature 425, 242. https:// doi.org/10.1038/425242a.

Bauer, N., Calvin, K., Emmerling, J., Fricko, O., Fujimori, S., Hilaire, J., Eom, J., Krey, V., Kriegler, E., Mouratiadou, I., Sytze de Boer, H., van den Berg, M., Carrara, S., Daioglou, V., Drouet, L., Edmonds, J.E., Gernaat, D., Havlik, P., Johnson, N., Klein, D., Kyle, P., Marangoni, G., Masui, T., Pietzcker, R.C., Strubegger, M., Wise, M., Riahi, K., van Vuuren, D.P., 2017. Shared socio-economic pathways of the energy sector - quantifying the narratives. Global Environ. Change 42, 316-330. https://doi.org/10.1016/J.GLOENVCHA.2016.07.006.

Bolin, B., 2007. A History of the Science and Politics of Climate Change: The Role of the Intergovernmental Panel on Climate Change. Cambridge University Press, New York. BP, 2018. BP Statistical Review of World Energy: June 2018.

Burck, J., Hagen, U., Marten, F., Höhne, N., Bals, C., 2018. The Climate Change Performance Index: Results 2019. Bonn. 
Castles, I., Henderson, D., 2003a. The IPCC Emission Scenarios: An Economic-Statistical Critique. Energy Environ. 14, 159-185. https://doi.org/10.1260/ 095830503765184583.

Castles, I., Henderson, D., 2003b. Economics, Emissions Scenarios and the Work of the IPCC. Energy Environ. 14, 415-435. https://doi.org/10.1260/ 095830503322364430.

Clinton, N.J., 2017. ExxonMobil and renewable energy group report progress in cellulosic biodiesel research | ExxonMobil [WWW Document]. ExxonMobile Newsroom. URL https://corporate.exxonmobil.com/en/News/Newsroom/Newsreleases/2017/1101_ExxonMobil-and-renewable-energy-group-report-progress-incellulosic-biodiesel-research (accessed 5.15.19).

Coady, D., Parry, I., Sears, L., Shang, B., 2017. How Large Are Global Fossil Fuel Subsidies? World Dev. 91, 11-27. https://doi.org/10.1016/J. WORLDDEV.2016.10.004.

Cremonese, L., Weger, L.B., Van der Gon, H.D., Bartels, M.P., Butler, T., 2019. Emission scenarios of a potential shale gas industry in Germany and the United Kingdom. Elem. Sci. Anth. 7, 18. https://doi.org/10.1525/elementa.359.

Doukas, A., DeAngelis, K., Ghio, N., Trout, K., Bast, E., Bossong, K., 2017. Talk is Cheap: How G20 Governments are Financing Climate Disaster [WWW Document]. URL http://priceofoil.org/content/uploads/2017/07/talk_is_cheap_G20_report_ July2017.pdf.

ExxonMobil, 2018. Mitigating emissions in our operations [WWW Document]. URL https://corporate.exxonmobil.com/Community-engagement/Sustainability-Report/ Managing-risks-of-climate-change/Mitigating-emissions-in-our-operations.

Farand, C., 2019. European Investment Bank ends lending to fossil fuel projects [WWW Document]. Climate Home news. URL https://www.climatechangenews.com/2019/ 11/15/european-investment-bank-ends-lending-fossil-fuel-projects/.

Flannery, B.P., 1985. CO2 Greenhouse update 1985 [WWW Document]. URL http:// www.climatefiles.com/exxonmobil/co2-research-program/1985-exxon-greenhouseresearch-budget/.

Friedlingstein, P., Jones, M.W., Sullivan, M., Andrew, R.M., Hauck, J., Peters, G.P., Peters, W., Pongratz, J., Sitch, S., Le Quéré, C., Bakker, D.C.E., Canadell, J.G., Ciais, P., Jackson, R.B., Anthoni, P., Barbero, L., Bastos, A., Bastrikov, V., Becker, M., Bopp, L., Buitenhuis, E., Chandra, N., Chevallier, F., Chini, L.P., Currie, K.I., Feely, R. A., Gehlen, M., Gilfillan, D., Gkritzalis, T., Goll, D.S., Gruber, N., Gutekunst, S., Harris, I., Haverd, V., Houghton, R.A., Hurtt, G., Ilyina, T., Jain, A.K., Joetzjer, E., Kaplan, J.O., Kato, E., Klein Goldewijk, K., Korsbakken, J.I., Landschützer, P., Lauvset, S.K., Lefèvre, N., Lenton, A., Lienert, S., Lombardozzi, D., Marland, G., McGuire, P.C., Melton, J.R., Metzl, N., Munro, D.R., Nabel, J.E.M.S., Nakaoka, S.-I., Neill, C., Omar, A.M., Ono, T., Peregon, A., Pierrot, D., Poulter, B., Rehder, G., Resplandy, L., Robertson, E., Rödenbeck, C., Séférian, R., Schwinger, J., Smith, N., Tans, P.P., Tian, H., Tilbrook, B., Tubiello, F.N., van der Werf, G.R., Wiltshire, A.J., Zaehle, S., 2019. Global carbon budget 2019. Earth Syst. Sci. Data 11, 1783-1838. https://doi.org/10.5194/essd-11-1783-2019.

Fujimori, S., Hasegawa, T., Masui, T., Takahashi, K., Herran, D.S., Dai, H., Hijioka, Y., Kainuma, M., 2017. SSP3: AIM implementation of shared socioeconomic pathways. Global Environ. Change 42, 268-283. https://doi.org/10.1016/j. gloenvcha.2016.06.009.

GCP, 2019. Supplemental data of Global Carbon Budget 2019 (Version 1.0) . https://doi. org/10.18160/gcp-2019.

Gray, V., 1998. The IPCC future projections: are they plausible? Climate Res.

Henderson, D., 2006. Governments and climate change issues: the case for a new approach. Energy Environ. 17, 619-632. https://doi.org/10.2307/44397268.

Henderson, D., 2005. SRES, IPCC and the treatment of economic issues: what has emerged? Energy Environ. 16, 549-578.

Henley, J., 2019. European Elections: triumphant Greens Demand More Radical Climate Action. The Guardian.

Holtsmark, B.J., Alfsen, K.H., 2005. PPP correction of the IPCC emission scenarios ? Does it matter? Clim. Change 68, 11-19. https://doi.org/10.1007/s10584-005-1310-2.

Hyndman, R.J., 2009. Moving averages.

IEA, 2018. Total primary energy supply (TPES): 1971-2016 [WWW Document]. World Energy Balances (2018 edition). URL http://wds.iea.org/WDS/.

IEA, 2019a. Total primary energy supply (TPES) by source, World 1990-2017 [WWW Document]. World Energy Balances 2019. International Energy Agency. URL https ://www.iea.org/statistics.

IEA, 2019b. World Energy Outlook 2019. International Energy Agency, Paris.

IPCC, 1990. Climate Change: The IPCC Response Strategies, Working Group III.

IPCC, 1991. Report of the 6th Session of the IPCC [WWW Document]. URL https://www. ipcc.ch/meetings/session06/sixth-session-report.pdf.

IPCC, 1996. Report of the Twelfth Session of the IPCC. Mexico City, 11-13 September, 1996.

IPCC, 2000. In: IPCC Special Report: Emission Scenarios. Summary for Policymakers. Intergovernmental Panel on Climate Change, Working Group III, Cambridge, England, p. 27.

IPCC, 2005. IPCC Expert meeting on emission scenarios, 12-14 January 2005, Washington. Washington DC.

IPCC, 2006. Report of the 25th session of the IPCC (Port Louis, Mauritius, 26-28 April 2006). Port Louis, Mauritius.

IPCC, 2007a. Towards new scenarios for analysis of emissions, climate change, impacts, and response strategies: Technical Summary. Noordwijkerhout, The Netherlands, 19-21 September, 2007.

IPCC, 2007b. AR4 Climate Change 2007: Mitigation of Climate Change.

IPCC, IPCC, 2014a. Climate Change 2014: Synthesis Report. Contribution of Working Groups I, II and III to the Fifth Assessment Report of the Intergovernmental Panel on Climate Change. IPCC, Geneva, Switzerland, p. 151.
IPCC, 2014b. Climate Change 2014 Mitigation of Climate Change. Cambridge University Press, Cambridge, United Kingdom and New York, NY, USA.

IRENA, 2019a. Global energy transformation: A roadmap to 2050 (2019 edition), International Renewable Energy Agency.

IRENA, 2019b. Renewable Power Generation Costs in 2018 [WWW Document] International Renewable Energy Agency. URL https://www.irena.org/publications/ 2019/May/Renewable-power-generation-costs-in-2018.

Kaya, Y., Yokobori, K., 1997. Environment, energy, and economy : strategies for sustainability. United Nations University Press.

Kriegler, E., Edmonds, J., Hallegatte, S., Ebi, K.L., Kram, T., Riahi, K., Winkler, H., van Vuuren, D.P., 2014. A new scenario framework for climate change research: the concept of shared climate policy assumptions. Clim. Change 122, 401-414. https:// doi.org/10.1007/s10584-013-0971-5.

Le Quéré, C., Jackson, R.B., Jones, M.W., Smith, A.J.P., Abernethy, S., Andrew, R.M., DeGol, A.J., Willis, D.R., Shan, Y., Canadell, J.G., Friedlingstein, P., Creutzig, F., Peters, G.P., 2020. Temporary reduction in daily global CO2 emissions during the COVID-19 forced confinement. Nat. Clim. Change 1-7. https://doi.org/10.1038/ s41558-020-0797-x.

Le Quéré, C., Raupach, M.R., Canadell, J.G., Marland, G., Bopp, L., Ciais, P., Conway, T. J., Doney, S.C., Feely, R.A., Foster, P., Friedlingstein, P., Gurney, K., Houghton, R.A., House, J.I., Huntingford, C., Levy, P.E., Lomas, M.R., Majkut, J., Metzl, N., Ometto, J.P., Peters, G.P., Prentice, I.C., Randerson, J.T., Running, S.W., Sarmiento, J.L., Schuster, U., Sitch, S., Takahashi, T., Viovy, N., van der Werf, G.R., Woodward, F.I., 2009. Trends in the sources and sinks of carbon dioxide. Nat. Geosci. 2, 831-836. https://doi.org/10.1038/ngeo689.

Leggett, J., Pepper, W.J., Swart, R.J., Edmonds, J., Meira Filho, L.G., Mintzer, I., Wang, M.X., Wasson, J., 1992. Emissions scenarios for the IPCC: an update. In: Climate change 1992: the supplementary report to the IPCC scientific assessment, pp. 69-95.

Levitz, E., 2018. Climate Change Polls: Voters Are Ready For a Green New Deal. New York Intelligencer.

Manne, A.S., Richels, R.G., Edmonds, J.A., 2005. Market exchange rates or purchasing power parity: does the choice make a difference to the climate debate? Clim. Change 71, 1-8. https://doi.org/10.1007/s10584-005-0470-4.

Manning, M.R., Edmonds, J., Emori, S., Grubler, A., Hibbard, K., Joos, F., Kainuma, M., Keeling, R.F., Kram, T., Manning, A.C., Meinshausen, M., Moss, R., Nakicenovic, N., Riahi, K., Rose, S.K., Smith, S., Swart, R., van Vuuren, D.P., 2010. Misrepresentation of the IPCC CO2 emission scenarios. Nat. Geosci. 3, 376-377. https://doi.org/ 10.1038/ngeo880.

Metayer, M., Breyer, C., Fell, H., 2015. The projections for the future and quality in the past of the World Energy Outlook for solar PV and other renewable energy technologies.

Montague, B., 2018. How David Henderson became an IPCC foe 2. https://doi.org/ Ecologist.

Moss, R.H., Edmonds, J.A., Hibbard, K.A., Manning, M.R., Rose, S.K., van Vuuren, D.P., Carter, T.R., Emori, S., Kainuma, M., Kram, T., Meehl, G.A., Mitchell, J.F.B., Nakicenovic, N., Riahi, K., Smith, S.J., Stouffer, R.J., Thomson, A.M., Weyant, J.P., Wilbanks, T.J., 2010. The next generation of scenarios for climate change research and assessment. Nature 463, 747-756. https://doi.org/10.1038/nature08823.

Nakicenovic, N., Swart, R., 2000. Special Report on Emissions Scenarios. Cambridge University Press, Cambridge, UK.

O'Neill, Brian C., Schweizer, Vanessa J., 2013. Systematic construction of global socioeconomic pathways using internally consistent element combinations. Climatic Change 122 (3), 431-445. https://doi.org/10.1007/s10584-013-0908-z.

O'Neill, B.C., Kriegler, E., Riahi, K., Ebi, K.L., Hallegatte, S., Carter, T.R., Mathur, R., van Vuuren, D.P., 2014. A new scenario framework for climate change research: the concept of shared socioeconomic pathways. Clim. Change 122, 387-400. https:// doi.org/10.1007/s10584-013-0905-2.

O’Neill, B.C., Tebaldi, C., van Vuuren, D.P., Eyring, V., Friedlingstein, P., Hurtt, G., Knutti, R., Kriegler, E., Lamarque, J.-F., Lowe, J., Meehl, G.A., Moss, R., Riahi, K., Sanderson, B.M., 2016. The Scenario Model Intercomparison Project (ScenarioMIP) for CMIP6. Geosci. Model Dev. 9, 3461-3482. https://doi.org/10.5194/gmd-93461-2016.

O’Neill, B.C., Kriegler, E., Ebi, K.L., Kemp-Benedict, E., Riahi, K., Rothman, D.S., van Ruijven, B.J., van Vuuren, D.P., Birkmann, J., Kok, K., Levy, M., Solecki, W., 2017. The roads ahead: Narratives for shared socioeconomic pathways describing world futures in the 21st century. Global Environ. Change 42, 169-180. https://doi.org/ 10.1016/j.gloenvcha.2015.01.004.

Observ'ER, 2019. The State of Renewable Energies in Europe. Edition 2018. 18th EurObserv'ER Report [WWW Document]. URL https://www.eurobserv-er.org/ category/2018/.

OECD/IEA, 2005. Energy Statistics Manual. Paris.

OECD, 2019. Environmental Policy Stringency Index [WWW Document]. OECD.stat. URL https://stats.oecd.org/Index.aspx?DataSetCode=EPS.

Parikh, J.K., 1992. IPCC strategies unfair to the South. Nature 1992 (360), 6404. https:// doi.org/10.1038/360507a0

Pedersen, Jiesper S.T., van Vuuren, Detlef P., Aparício, Bruno A., Swart, Rob, Gupta, Joyeeta, Santos, Filipe D., et al., 2020. Variability in historical emissions trends suggests a need for a wide range of global scenarios and regional analyses. Communications Earth \& Environment 1 (41). https://doi.org/10.1038/s43247020-00045-y.

Pepper, W.J., Leggett, R.J., Swart, R.J., Wasson, J., Edmonds, J., Mintzer, I., 1992. Emission Scenarios for the IPCC. An Update. Assumptions, Methodology, and Results. Washington, D.C. 
Peters, G.P., Andrew, R.M., Boden, T., Canadell, J.G., Ciais, P., Le Quéré, C., Marland, G., Raupach, M.R., Wilson, C., 2013. The challenge to keep global warming below $2{ }^{\circ} \mathrm{C}$. Nat. Clim. Change 3, 4-6. https://doi.org/10.1038/nclimate1783.

Peters, G.P., Davis, S.J., Andrew, R., 2012. A synthesis of carbon in international trade Biogeosciences 9, 3247-3276. https://doi.org/10.5194/bg-9-3247-2012.

Pretis, F., Roser, M., 2017. Carbon dioxide emission-intensity in climate projections: Comparing the observational record to socio-economic scenarios. Energy (Oxford, England) 135, 718-725. https://doi.org/10.1016/j.energy.2017.06.119.

Raupach, M.R., Marland, G., Ciais, P., Le Quéré, C., Canadell, J.G., Klepper, G., Field, C. B., 2007. Global and regional drivers of accelerating CO2 emissions. PNAS 104, 10288-10293. https://doi.org/10.1073/pnas.0700609104.

Reheis-Boyd, C., 2014. WSPA Priority Issues Western States Petroleum Association.

Riahi, K., van Vuuren, D.P., Kriegler, E., Edmonds, J., O'Neill, B.C., Fujimori, S., Bauer N., Calvin, K., Dellink, R., Fricko, O., Lutz, W., Popp, A., Cuaresma, J.C., KC, S., Leimbach, M., Jiang, L., Kram, T., Rao, S., Emmerling, J., Ebi, K., Hasegawa, T., Havlik, P., Humpenöder, F., Da Silva, L.A., Smith, S., Stehfest, E., Bosetti, V., Eom, J., Gernaat, D., Masui, T., Rogelj, J., Strefler, J., Drouet, L., Krey, V., Luderer, G., Harmsen, M., Takahashi, K., Baumstark, L., Doelman, J.C., Kainuma, M., Klimont, Z., Marangoni, G., Lotze-Campen, H., Obersteiner, M., Tabeau, A., Tavoni, M., 2017. The Shared Socioeconomic Pathways and their energy, land use, and greenhouse gas emissions implications: An overview. Global Environmental Change 42, 153-168. https://doi.org/10.1016/j.gloenvcha.2016.05.009.

Richels, R.G., Tol, R.S.J., Yohe, G.W., 2008. Future scenarios for emissions need continual adjustment. Nature 453, 155. https://doi.org/10.1038/453155a.

Shukla, P.R., 2004. Climate Policy Assessment for India: Applications of Asia-Pacific Integrated Model (AIM). Universities Press.

Economist, The, 2003. Hot potato. Economist.

Tol, R.S.J., 2005. Memorandum by Professor Richard S J Tol, Hamburg, Vrije and Carnegie Mellon Universities. Second Report, Economic Affairs Committee, Economic Affairs.
Tollefson, J., 2020. How hot will Earth get by 2100? Nature 580, 443-445. https://doi. org/10.1038/d41586-020-01125-x.

United Nations Statistics Division, 2020. Total population, both sexes combined (thousands) [WWW Document]. UNdata. http://data.un.org/Data.aspx?d=Pop Div\& $\mathrm{f}=$ variableID\%3A12.

Van Vuuren, D.P., Alfsen, K.H., 2006. PPP versus MER: searching for answers in a multidimensional debate. Clim. Change 75, 47-57. https://doi.org/10.1007/s10584-0059045-7.

van Vuuren, D.P., Edmonds, J., Kainuma, M., Riahi, K., Thomson, A., Hibbard, K., Hurtt, G.C., Kram, T., Krey, V., Lamarque, J.-F., Masui, T., Meinshausen, M., Nakicenovic, N., Smith, S.J., Rose, S.K., 2011. The representative concentration pathways: an overview. Clim. Change 109, 5-31. https://doi.org/10.1007/s10584011-0148-Z.

van Vuuren, D.P., Edmonds, J., Smith, S.J., Calvin, K.V., Karas, J., Kainuma, M., Nakicenovic, N., Riahi, K., van Ruijven, B.J., Swart, R., Thomson, A., 2010. What do near-term observations tell us about long-term developments in greenhouse gas emissions? Clim. Change 103, 635-642. https://doi.org/10.1007/s10584-010-99404.

van Vuuren, D.P., Kok, M.T.J., Girod, B., Lucas, P.L., de Vries, B., 2012. Scenarios in global environmental assessments: key characteristics and lessons for future use. Global Environ. Change 22, 884-895. https://doi.org/10.1016/J. GLOENVCHA.2012.06.001.

van Vuuren, D.P., O'Neill, B.C., 2006. The consistency of IPCC's SRES scenarios to 1990-2000 trends and recent projections. Clim. Change 75, 9-46. https://doi.org/ 10.1007/s10584-005-9031-0.

WB, 2019a. Population, total [WWW Document]. The World Bank Data. URL https:// data.worldbank.org/indicator/SP.POP.TOTL (accessed 4.16.19).

WB, 2019b. GDP (constant 2010 US\$) [WWW Document]. The World Bank Data. URL https://data.worldbank.org/indicator/NY.GDP.MKTP.KD.

WB, 2019. GDP, PPP (constant 2011 international \$) [WWW Document]. The World bank Data. URL https://data.worldbank.org/indicator/NY.GDP.MKTP.PP.KD. 